\title{
Por que comparar os direitos no século XIX?*
}

\author{
Why compare legal systems in the $19^{\text {th }}$ century?
}

Sylvain Soleil ${ }^{* *}$

\section{REFERÊNCIA}

SOLEIL, Sylvain. Por que comparar os direitos no século XIX? Revista da Faculdade de Direito da UFRGS, Porto Alegre, n. 44, p. 182-228, dez. 2020. DOI: <https://doi.org/10.22456/0104-6594.109644>.

\section{RESUMO}

Inúmeros autores europeus e norte-americanos, fossem juristas ou não, compararam os direitos bem antes da formalização de uma disciplina jurídica específica, na virada do séc. XIX ao séc. XX. Este artigo examina um conjunto de obras e artigos do séc. XIX buscando identificar as motivações e seus autores e determinar a diversidade e complementaridade das abordagens. Trata-se de criticar, promover e reformar; oferecer os dados, expor as legislações, classificar; indicar linhas diretivas para reger e julgar; relatar a diversidade de abordagens entre os sistemas jurídicos; auxiliar no desenvolvimento de teorias históricas; unificar o direito em vigor.

\section{PALAVRAS-CHAVE}

Direito comparado; Doutrina jurídica; séc. XIX.

\begin{abstract}
Many European and American authors, whether legal experts or not, compared legal systems even before a specific legal discipline was formalized at the turn of the $19^{\text {th }}$ and $20^{\text {th }}$ centuries. This paper analyses a body of nineteenth-century books and articles in order to identify the motivations of their authors and determine how far their approaches differ from or complete each other. The aims were many: to criticize, promote and reform; to provide legal information, present and classify laws; to provide governments or judges with some guidelines; to highlight the diversity of approaches among legal systems; to help develop historical theories; to unify existing laws.
\end{abstract}

\section{KEYWORDS}

Compative Law; Legal Doctrine; Nineteenth Century.

\section{SUMÁRIO}

1. Introdução. 2. Comparar para criticar, promover, reformar. 3. Comparar para oferecer os dados, expor as legislações, classificar. 4. Comparar para indicar como reger e julgar. 5. Comparar para relatar a diversidade. 6. Comparar para alimentar teorias históricas. 7. Comparar para unificar o direito. 8. Conclusão. Referências. Dados da publicação.

\footnotetext{
* Texto original em língua francesa: SOLEIL, Sylvain. Pourquoi comparait-on les droits au XIXe siècle. Revue Clio@Themis, n. 13, p. 01-21, 2017. Tradução para a língua portuguesa por Alan Wruck Rangel (Pósdoutorando no PPGD-UERJ). Revisão da tradução por Alfredo de J. Flores (Professor Permanente do PPGDUFRGS).

** Professor de Introdução ao Direito e de História do Processo na Faculdade de Direito e de Ciência Política da Universidade de Rennes I, França. Pesquisador de Teoria e História dos Sistemas Jurídicos pela mesma instituição.
} 


\section{INTRODUÇÃO}

É fato notório que se comparavam os direitos bem antes da formalização do direito comparado enquanto disciplina jurídica específica ${ }^{1}$. No século XIX, essa comparação se desdobra de maneira variada, por motivos muito diversos e sem disciplina comum (no duplo sentido de um domínio particular do conhecimento e do conjunto de regras que regem os atores). Muitos autores europeus e americanos comparam os direitos, com ou sem método científico, com ou sem amplitude, com ou sem consciência de fazer uma comparação jurídica. Nessas obras e artigos, não se trata propriamente de direito comparado, no sentido que entenderão os autores na virada do século XIX para o séc. XX, mas se trata concretamente, de reunir no espaço e/ou no tempo as instituições, os princípios, os mecanismos, até mesmo sistemas jurídicos inteiros, e assinalar suas particularidades, suas diferenças e suas semelhanças. Como dar conta de um campo intelectual tão vasto?

Existe evidentemente várias abordagens complementares. A primeira consiste em fazer uso da prosopografia e do estudo biográfico, interessando-se, país por país, às grandes figuras da comparação jurídica - por exemplo Savigny, Feuerbach ou Mittermaier na Alemanha, Foelix ou Laboulaye na França, Amari ou Zuppetta na Itália, Burge ou Maine no Reino Unido, Cooper ou Story nos Estados Unidos². A segunda consiste numa abordagem pela história do pensamento jurídico, examinando notadamente as redes intelectuais, as

\footnotetext{
${ }^{1}$ Para algumas retrospectivas, ver: SCARCIGLIA, Roberto. A brief history of legal comparison: A lesson from the Ancient to Post-Modern times. Beijing Law Review, v. 6, n. 4, p. 296-310, 2015; DONAHUE, Charles. Comparative Law before the Code Napoléon. In: REIMANN, Mathias; ZIMMERMANN, Reinhard (Orgs.). The Oxford Handbook of Comparative Law. [s.1.]: Oxford University Press, 2006, p. 02-32; PADOA-SCHIOPPA, Antonio. La comparazione giuridica tra Ottocento e Novecento: in memoria di Mario Rotondi, 6 novembre 1998. Milano: Istituto lombardo di scienze e lettere, 2001. (Incontro di studio); BAUMAN, R. Comparative law in ancient times. In: TAY, A (Org.). Law and Australian Thinking in the 1980s. Sidney: Organizing Committee of the 12th International Congress of Comparative Law, 1986, p. 99 e ss; GORLA, Gino. Prolegomeni ad una storia del diritto comparato europeo. Il Foro Italiano, v. 103, 1980, p. 11 e ss.

${ }^{2}$ Os dicionários biográficos oferecem elementos úteis : ARABEYRE, Patrick; HALPÉRIN, Jean-Louis; KRYNEN, Jacques (Orgs.). Dictionnaire historique des juristes français (XIIe - XXe siècle). Paris: Presses Universitaires de France, 2007; BIROCCHI, Italo; CORTESE, Ennio; MATTONE, Antonello; et al. (Orgs.). Dizionario biografico dei Giuristi italiani (XII-XX secolo). Bologna: Società Editrice il Mulino, 2013. 2v.; PELÁEZ, Manuel J. (Org.). Diccionario crítico de juristas españoles, portugueses y latinoamericanos (hispánicos, brasilleños, quebequenses y restantes francófonos). Málaga, Zaragoza, Barcelona: Ed. Universidad de Málaga, 2005. 5v.; STOLLEIS, Michael (Org.). Juristen: ein biographisches Lexikon; von der Antike bis zum 20. Jahrhundert. 1. Aufl. München: Beck, 2001. (Beck'sche Reihe, 1417); BRAUNEDER, Willhelm. Juristen in Österreich: 1200-1980. Viena: Verlag Orac, 1986; MATTHEW, H. C. G.; HARRISON, Brian Howard; BRITISH ACADEMY (Orgs.). Oxford dictionary of national biography: in association with the British Academy: from the earliest times to the year 2000. Oxford; New York: Oxford University Press, 2004. 62v.; NEWMAN, Roger K. The Yale Biographical Dictionary of American Law. New Haven: Yale University Press, 2009.
} 
correntes e as escolas de pensamento que recorreram à comparação, por exemplo a escola histórica, a corrente eclética ou escola científica ${ }^{3}$. A terceira consiste numa abordagem de modo retrospectivo, examinando a gestação do direito comparado por áreas geográficas ou identificando as heranças paralelas (universalista, funcionalista etc.) ${ }^{4}$.

Se propõe aqui, como chave de análise, de questionar, hic et nunc, os diversos motivos ("mobiles") que animam aqueles que comparam os direitos no século XIX. Trata-se de reunir um corpus de trabalhos - essencialmente, mas não unicamente obra de juristas - escolhidos

\footnotetext{
${ }^{3}$ Trabalhos históricos oferecem elementos úteis. Dentre outros vários títulos: P. Grossi, GROSSI, Paolo. Scienza giuridica italiana: un profilo storico, 1860-1950. Milão: Giuffrè, 2000; FEOLA, Raffaele. Instituzioni e cultura giuridica. Naples: Ed. Scientifiche Italiani, 1993. 3v.; SMITH, Keith John Michael. Lawyers, Legislators, and Theorists: Developments in English Criminal Jurisprudence, 1800-1957. Oxford: Clarendon Press, 1998; LOBBAN, Michael. A history of the philosophy of law in the common law world, 1600-1900. Londres: Springer, 2002; GUYON, Gwenaël. Les partisans de la codification en Angleterre (XIXe siècle) : La question du droit pénal entre utilitarisme, modernisation du common law et modèle juridique français. Tese, Rennes 1, Rennes, 2012; SARIÑENA, Marta María Lorente. La Doctrina legal y el silenciamiento de los juristas en una España sin código (1808-1889). Quaderni fiorentini per la storia del pensiero giuridico moderno, v. 40, n. 1, p. 135-175, 2011; JOUANJAN, Olivier. Une histoire de la pensée juridique en Allemagne (1800 - 1918): idéalisme et conceptualisme chez les juristes allemands du XIXe siècle. 1. ed. Paris: Presses Univ. de France, 2005; HALPÉRIN, Jean-Louis. Histoire de l'état des juristes - Allemagne, XIXe-XXe siècles. Paris: Garnier, 2015; RABBAN, David M. Law's history: American legal thought and the transatlantic turn to history. Cambridge: Cambridge Univ. Press, 2013. (Cambridge historical studies in American law and society); FALÉLAVAKI, Yannick. L'histoire d'une conversion: la doctrine française du XIXe siècle et le recours à la comparaison juridique. Tese, Rennes 1, Rennes, 2016; DUBOUCHET, Paul. La pensée juridique avant et après le Code civil. Lyon: L' Hermès, 1992; JESTAZ, Philippe; JAMIN, Christophe. La doctrine. Paris: Dalloz, 2004. (Méthodes du droit) ; GAUDEMET, Jean. Les Écoles historiques du droit en France et en Allemagne. Revue d'histoire des facultés de droit et de la science juridique, v. 19, p. 87-124, 1998; MOTTE, Olivier. Savigny et la France. Berne, Suisse: P. Lang, 1983; RÉMY, Philippe. Eloge de l'exégèse. Droits. Revue française de théorie juridique., n. 1, p. 115 et seq., 1985; PRADEL, J. Histoire des doctrines pénales. Paris : Presses universitaires de France, 1991; TOUZEIL-DIVINA, Mathieu. La doctrine publiciste, 1800-1880: éléments de patristique administrative. Paris: Éd. La Mémoire du Droit, 2009; HAKIM, Nader. L'autorité de la doctrine civiliste française au XIXe siécle. Paris: L.G.D.J, 2002. (Bibliothèque de droit privé, t. 381); POUTHIER, Tristan. Droit naturel et droits individuels en France au dix-neuvième siècle. Tese, Paris II, 2013; VENTRE-DENIS, Madeleine. Joseph-Elzear Ortolan (1802-1873), un juriste dans son siècle. Revue d'histoire des facultés de droit et de la science juridique, $\mathrm{n}^{\circ}$ 16, p. 173-239, 1995; HAKIM, Nader; MELLERAY, Fabrice (Orgs.). Le renouveau de la doctrine française: les grands auteurs de la pensée juridique au tournant du XXe siècle. Paris: Dalloz, 2009. (Méthodes du droit); HERRERA, Carlos-Miguel. Les juristes face au politique le droit, la gauche, la doctrine sous la Troisième République. Paris: Éd. Kimé, 2005. 2v.; DEROUSSIN, David (Org.). Le renouvellement des sciences sociales et juridiques sous la IIIe République: la Faculté de droit de Lyon. Paris: Éd. La Mémoire du Droit, 2007. (Collection Recueil d'études, 2).

${ }^{4}$ Os trabalhos dos comparatistas oferecem elementos úteis. Dois exemplos: em 2006, Reimann e Zimmermann (REIMANN, Mathias; ZIMMERMANN, Reinhard (Orgs.). The Oxford Handbook of Comparative Law. [s.1.]: Oxford University Press, 2006, p. 2-32.), propõe seguir, de modo retrospectivo, o desenvolvimento do direito comparado na França (B. Fauvarque-Cosson), Alemanha, Suíça e Áustria (I. Schwenzer), Itália (E. Grande), Reino-Unido (J. Cairns), Estados-Unidos (D. Clark), Europa central e oriental (Z. Kühn), Ásia do Leste (Z. Kitagawa) e América Latina (J. Kleinheisterkamp) ; em 2000, ao momento do centenaio do Congresso de Paris, os comparatistas reunidos em Cambridge por Pierre Legrand e Roderick Munday discutiram quatro heranças: universalista (J. Gordley), colonial (U. Braxi), nacionalista (H. P. Glenn), funcionalista (M. Graziadei) LEGRAND, Pierre; MUNDAY, Roderick J. C. (Orgs.). Comparative legal studies: traditions and transitions. Cambridge: Cambridge Univ. Press, 2003.

${ }^{5}$ N. do T.: optamos por manter, ao lado da tradução, o termo original utilizado pelo autor ("mobile [s]") em virtude da ênfase na motivação ou mobilização pessoal para o agir.
} 
precisamente por sua heterogeneidade, e por concentrar a análise sobre o momento no qual o autor passa ao ato de escrever, em tal obra ou tal artigo em particular. Por que o autor, universitário ou não, autêntico comparatista ou não, membro de uma escola de pensamento ou não, faz a escolha de reunir dispositivos, princípios ou sistemas jurídicos estrangeiros e assinalar, de uma maneira ou outra, as singularidades? Em que seu projeto editorial o conduz a comparar os direitos? Questionar sobre as motivações, é buscar a intenção consciente ou inconsciente, a intenção real ou simulada, em ligação com as finalidades almejadas. É buscar o que anima o autor quando ele compara - às vezes, este o explica (advertência, introdução, nota, correspondência); às vezes, é a natureza mesma da comparação que informa sobre sua razão de ser e, portanto, sobre a motivação do autor. Paralelamente, questionar sobre os motivos, é também jogar alguma luz sobre o que o autor mobiliza: os dados jurídicos que serão comparados, as traduções, a maneira de operar a comparação, o discurso que, às vezes, acompanha e justifica a comparação. É, portanto, nos dar conta da diversidade das abordagens, indo de simples notas comparativas, que o leitor não identifica forçosamente em uma primeira leitura, até os projetos pensados, amplos e assumidos; esses projetos que, no final do século, irão preparar o terreno do direito comparado enquanto disciplina específica. Interrogar-se sobre as motivações ("mobiles"), é ainda tomar consciência de um certo número de imbricações e de falsas pistas possíveis: as mobilizações podem ser múltiplas e se entrelaçar na mesma obra6; um motivo avançado pode esconder um outro ${ }^{7}$; a motivação do autor pode se conceber somente à luz das expectativas do leitor ${ }^{8}$.

\footnotetext{
${ }^{6}$ Em 1855, Laboulaye, ao momento da criação da Revue historique de droit français et étranger, preza pela história e pela comparação do direito, tanto para compreender como vão e veem os modelos jurídicos de um pais a outro, como para mostrar como os povos e seus direitos atravessam os mesmos "estágios de civilização" segundo as leis da evolução. Ver HALPÉRIN, Jean-Louis. Laboulaye, historien du droit et/ou comparatiste. Revue internationale de droit comparé, v. 63, n. 3, p. 517-525, 2011.

${ }^{7}$ Em 1823, no momento de sua conferência pronunciada no Historical Society de New York, o norte-americano Sampson propõe questionar sabiamente a natureza e origem common law inglesa com relação ao civil law, mas a totalidade de suas críticas e sua correspondência anterior mostram que o seu verdadeiro motivo ('mobile') é ridicularizar a commom law para a substituir, nos Estados-Unidos, por um direito codificado a partir do modelo francês. Alguns meses antes de pronunciar seu discurso, Sampson enviou a Duponceau um esboço do discurso. Este último responde a Sampson com regozijo da boa oportunidade que ele está prestes a desfrutar com o seu público. Ver HENDERSON, Jennifer Denise. Blaze of Reputation and the Echo of a Name: The Legal Career of Peter Stephen du Ponceau in Post-Revolutionary Philadelphia. Tese, The Florida State University, Tallahassee, Florida, 2004, p. 67.

${ }^{8}$ Em 1840, Anthoine de Saint-Joseph publica tabelas de concordância entre as legislações civis de um quinzena de países, não só para apresentar dados sobre o estado do direito no mundo, mas também para atender às necessidades de três tipos de leitores: aqueles que estudam a evolução da legislação civil, aqueles que buscam formas de melhorar e aperfeiçoar seu direito nacional, aqueles que buscam fundar o direito como uma ciência. Ver MERGEY, Anthony. Le réseau constitué autour d'Anthoine de Saint-Joseph et de la Concordance entre les codes civils étrangers et le Code Napoléon. Entre exaltation d'un nationalisme juridique modéré et promotion
} 
O exame revela assim uma diversidade/complementariedade de motivações (“mobiles"): 1) criticar, promover, reformar; 2) oferecer os dados, expor as legislações, classificar; 3) indicar como reger ou julgar; 4) relatar a diversidade; 5) alimentar teorias históricas; 6) unificar o direito em vigor.

\section{COMPARAR PARA CRITICAR, PROMOVER, REFORMAR}

O autor do século XIX pode ter por motivação principal pesar as vantagens e inconvenientes respectivos daquele ou deste dispositivo, de criticar ou de promover uma norma nacional pela comparação com uma norma estrangeira, de convidar o legislador a fazer escolhas e operar reformas.

Na França, basta percorrer a Revue Foelix (1834-1850), a Revue de législation et de jurisprudence ou Revue Wolowski (1835-1869), a Revue pratique de droit français (18561869) ou as revistas jurídicas da segunda metade do século, para constatar que esse motivo é onipresente; ou que o autor propõe uma verdadeira comparação entre dois ou vários modelos, ou que se contenta em elogiar (ou desaprovar) uma legislação estrangeira em detrimento (ou em proveito) da norma nacional em vigor ${ }^{9}$. No exterior, basta examinar alguns dos maiores projetos editoriais e os debates mais acalorados do século... Sampson e os radical codificationists americanos dos anos de 1825 comparam o triste estado do Common law britânico e norte-americano com a codificação napoleônica, para fazer desta um modelo jurídico e sublinhar as suas vantagens: clareza e rigor das regras, lógica dedutiva, acessibilidade ao direito ${ }^{10}$. O britânico Humphreys publica suas Observations on the Actual Situation of English Laws of Real Property, with the Outlines of a Code (1826) e compara o regime de propriedade na França e no Reino Unido, para propor "um remédio aos defeitos da

d'un fonds juridique commun. In: LE YONCOURT, Thiphaine (Org.). L'Idée de fonds juridique commun dans l'Europe du XIXe siècle: les modèles, les réformateurs, les réseaux. Rennes: Presses universitaires de Rennes, 2014. (Collection "L'univers des normes"), p. 187 et seq.

${ }^{9}$ FALÉLAVAKI, Yannick. L'histoire d'une conversion: la doctrine française du XIXe siècle et le recours à la comparaison juridique. Tese, Rennes 1, Rennes, 2016, p. 208 et seq., p. 335 et seq.; KEISTINE, Jacques-Olivier. La revue Foelix (de 1834 à 1843). Un miroir allemand pour la science du Droit en France. These de doctorat, Université Paris-Est Marne-la-Vallée, Marne-la-Vallée, 2011; CANTO, Patrick. La revue de législation et de jurisprudence: 1835-1853. Tese (Direito) - Université de Lyon Jean Moulin, 1999.

10 THOMPSON, Pishey (Org.). Sampson's Discourse, and correspondence with various learned jurists, upon the history of the law, with the addition of several essays, tracts, and documents, relating to the subject. Washington city: Gales \& Seaton, 1826. Ver: A. Mergey, A. ; SOLEIL, Sylvain. Faut-il codifier le common law des États-Unis ? La controverse Sampson vs Duponceaux (1823-1826). In : CORNU-THÉNARD, N. ; MERGEY, A. ; SOLEIL, S. (dir.). La controverse. Rennes : [s. n.], 2017, no prelo. 
propriedade real" inglesa ${ }^{11}$. O britânico Bentham, em seu Constitutional Code (1830), investiga, em termos de direito constitucional, as origens de uma constituição perfeita comparando (evidentemente, em detrimento da primeira) a constituição inglesa à constituição americana $^{12}$. O alemão Mittermaier, em Die Lehre vom Beweise im deutschen Strafprozesse (1834), propõe fazer um exame aprofundado dos monumentos legislativos e doutrinários da Inglaterra, França, Áustria e dos vários estados alemães, a fim, diz ele, "de saber se o direito alemão organizou sabiamente as provas criminais de forma sistemática [isto é, adotar o sistema de provas legais, em vez do da intimação convicção]" ${ }^{13}$. Os espanhóis Silvela, Burgos, Oliván, Ortiz de Zúñiga, Gómez de la Serna ou Posada Herrera, em seus tratados de direito administrativo dos anos 1839-1845, comparam os diversos modelos (Áustria, Prússia, França, Bélgica, Portugal, Brasil, repúblicas latino-americanas, Estados Unidos, Reino Unido) para incentivar a centralização e autoridade do Conselho de Estado e dos ministros, para modernizar as instituições administrativas locais, para proibir o juiz do judiciário de tratar do contencioso administrativo ${ }^{14}$. $\mathrm{O}$ romeno Boerescu, em sua tese La Roumanie après le Traité de Paris du 30 mars 1856 (1859), examina o direito interno da Moldo-Wallakia e o compara ao da França, para promover a modernidade francesa em matéria de administração, justiça,

\footnotetext{
${ }^{11}$ HUMPHREYS, James. Observations on the actual situation of english law of real property, with the outlines of a Code. Londres: [s. n.], 1826. Ver SOLEIL, Sylvain. In the Order of the Code Napoleon. Les carences du droit anglais au révélateur du modèle juridique français (1820-1840). In: GASNIER, F.; BLANCHARD, C. (Orgs.). Aux confins du droit, hommage amical à Xavier Martin. POitiers: LGDJ, Presses Universitaires de Poitiers, 2015, p. 377-397.

${ }^{12}$ BENTHAM, Jeremy. Constitutional Code (1830), the works of Jeremy Bentham published under the superintendence of his executor, John Bowring. Edimburgo: [s. n.], 1843. 9v. v. IX, p. 9. Ver: TUSSEAU, Guillaume. Jeremy Bentham et le droit constitutionnel: une approche de l'utilitarisme juridique. Paris: L'Harmattan, 2003. (Collection Logiques politiques). p. 227 et seq.

${ }^{13}$ MITTERMAIER, Carl Joseph Anton. Traité de la preuve en matière criminelle ou exposition comparée des principes de la preuve en matière criminelle, etc., et de ses applications diverses en Allemagne, en France, en Angleterre, etc. Trad. C. A. Alexandre. Paris: Cosse et N. Delamotte, 1848, p. xi.

${ }^{14}$ SILVELA, Francisco Agustín. Colección de proyectos, dictámenes y leyes orgánicas, o estudios prácticos de administración. Madrid: Imprenta nacional, 1839; ORTIZ DE ZÚÑIGA, M. Elementos de derecho administrativo. 3 vol. Granada; Imprenta e Librería de Sanz, 1842-1843; GÓMEZ DE LA SERNA, P. Instituciones del derecho administrativo español. Madrid: D. Vincente de Lalama, 1843. 2v.; OLIVÁN, A. De la administración con relación a España. Madrid: Boix, 1843; POSADA DE HERRERA, J. Lecciones de administración. Madrid: Establecimento tipografico, 1843. 3v.; MARQUÉS DE VALGONERA. Consejo de Estado. Revista de Madrid, 1839, apud GALLOSTRA Y FRAU, Colección bibliográphica de lo contenciosoadministrativo. Madrid: Imprenta y Fundición de Manuel Tello, 1881. p. 117. Ver: CHAMOCHO, Miguel Angel. Les réformes administratives provinciales en Espagne et le modèle français au milieu du XIXè siècle. Revue historique de droit français et étranger, n. 3, p. 415-435, 2007. Do mesmo autor : CHAMOCHO, Miguel Angel. Le contentieux administratif en Espagne au XIXe siècle: entre particularismes et importation du modèle français. In: HAUTEBERT, J.; SOLEIL, S. (Orgs.). Modèles français, enjeux pollitiques et élaboration des grands textes de procédure en Europe. Paris: Éditions juridiques techniques, 2007, v. 1, p. 219 e ss. 2v.; NEIRA, M. Martínez. Relevancia del derecho administrativo francés en la educación jurídica española : les différentes façons de percevoir et d'utiliser le droit français en tant que modèle juridique dans l'Europe du XIXe siècle. Forum Historiae Iuris, 2005, § 5. Disponível na internet: 〈www.forhistiur.de〉.
} 
direito e codificação ${ }^{15}$. Os italianos Guastala, Carcano ou Sampolo compararam, nos anos 1860-1885, a cassação francesa à revisão alemã para alimentar a controvérsia sobre o caminho que o legislador italiano deveria tomar ${ }^{16}$. Sampolo exclama - e isto poderia ser a palavra de ordem de todos esses autores ${ }^{17}$ :

Graças à legislação comparada (la legislazione comparata), que reduz as fronteiras, aproxima os povos; as leis dos diferentes Estados são julgadas umas com relação às outras e, comparando-as, distinguem-se as mais justas e as mais fecundas e, assim, se adquirem lições úteis.

A comparação dos direitos para criticar, promover ou reformar constitui, sem dúvida, no século XIX, a atividade mais poderosa e a motivação (“mobile”) mais frequentemente invocado. Isso é facilmente explicado. A fundação, no mundo, de uma multiplicidade de novos Estados e o gigantesco impulso de reformas nos antigos Estados suscitam, por toda a parte, a mobilização do passado e de modelos estrangeiros (no sentido de sistemas jurídicos de referência, simplificados, modelados por facilitar a comparação) para debater e propor modelos a seguir (no sentido de sistemas jurídicos a imitar).

Principalmente porque, por trás do autor, se perfila às vezes o reformador: Pisanelli, Stephen ou Boissonade seriam exemplos perfeitos. Giuseppe Pisanelli é advogado e professor universitário, reconhecido como o especialista italiano em processo civil no século XIX. Em 1855, participa da publicação do Commentario del codice di procedura civile per gli Stati Sardi, na qual faz uma comparação entre autores italianos, franceses e alemães: "de acordo com a cultura jurídica da época, caracterizada pelo que se denomina ecletismo jurídico, ele recorre à comparação jurídica que ele concebe como um instrumento indispensável para guiar as escolhas do legislador"18. Tendo-se tornado Ministro da Justiça (1862-1864), trabalhará doravante pela unificação do direito civil e do direito processual e fará com que seja aprovado

\footnotetext{
${ }^{15}$ BOERESCU, Vasile. La Roumanie après le Traité de Paris du 30 mars 1856. Paris: [s. n.], 1859. Ver: GUTAN, M. La réception de l'institution napoléonienne du préfet en Roumanie. In: MOQUET-ANGER, MarieLaure (Org.). Les institutions napoléoniennes. Paris: L'Harmattan, 2006, p. 65, nota 1.; SOLEIL, Sylvain. Vasile Boerescu. In: LE YONCOURT, Thiphaine (Org.). L'Idée de fonds juridique commun dans l'Europe du XIXe siècle: les modèles, les réformateurs, les réseaux. Rennes: Presses universitaires de Rennes, 2014. (Collection "L'univers des normes"), p. 245 et seq.

${ }^{16}$ GUASTALLA, M. Ordinamento giudiziario: supremo stadio di giurisdizione. La legge, n. I, p. 61 et seq., 1861; CARCANO, G. Cassazione o terza instanza? Monitore dei tribunali, p. 974 et seq., 1871. p. 1061 et seq.

17 SAMPOLO, L. Cenni intorno all'ordinamento giudiziario nell'Impero germanico riscontrato con quello d'Italia. In: Il círcolo giuridico, 1885, p. 250 apud MECCARELLI, Massimo. Le corti di cassazione nell'Italia Unita. Profili sistematici e costituzionali della giurisdizione in una prospettiva comparata (1865-1923). Milão: Giuffrè, 2005.

${ }^{18}$ SOLIMANO, Stefano. Codice di procedura civile italiano del 1865. In: SOLEIL, S.; HAUTEBERT, J. (Orgs.). La procédure et la construction de l'État en Europe (XVI e-XIX e siècles). Recueil de textes, présentés et commentés. Rennes: Presses universitaires de Rennes, 2011, p. 248.
} 
o Codice di procedura civile italiano (1865). James Fitzjames Stephen é um jurista, autor, em 1863, do General View of the Criminal Law of England, o primeiro trabalho abrangente sobre o sistema penal inglês desde Blackstone. Esta obra, corrigida, torna-se um Digest of Criminal Law (crimes and punishments), publicado em 1877, com base no qual Stephen propôs, em 1878, ao lord chancelor Cairns e ao procurador-geral Holker, um projeto de código penal e processo. Com o seu acordo e sob a sua autoridade, Stephen redigirá o anteprojeto de código (Draft Criminal Code de 1878), que será apresentado ao Parlamento pelo procurador-geral na sessão de $1878^{19}$. Gustave Boissonade é um professor parisiense que publica diversos estudos de legislação comparada nos anos $1868-1874^{20}$, antes de ser contratado pelo governo japonês para trabalhar na reforma do ensino universitário e "ajudar na preparação de leis e outros trabalhos regulatórios e de consultoria, como um legista a serviço do governo”. Este trabalho se concretiza em um código penal, um código de processo penal e um projeto de código civil $^{21}$.

Em suma, com todos esses autores que se tornaram reformadores, o recurso à comparação é uma necessidade: comparar, avaliar, escolher; o método é universal ${ }^{22}$. Com um olhar retrospectivo sobre a função primeira do direito comparado no século XIX, Yntema havia corretamente concluído em 1958: "Sem dúvida, o motivo imediato do direito comparado foi frequentemente utilitário. É muito mais fácil imitar um modelo estrangeiro de legislação que teve sucesso do que inventar um novo"23.

\footnotetext{
${ }^{19}$ GUYON, Gwenaël. Les partisans de la codification en Angleterre (XIXe siècle) : la question du droit pénal entre utilitarisme, modernisation du common law et modèle juridique français. Tese, Rennes 1, Rennes, 2012, p. 343 et seq.

${ }^{20}$ BOISSONADE, Gustave. Le nouveau code civil italien comparé au Code Napoléon. Revue Pratique de droit français, v. XXVI, 1868. e, do mesmo autor, BOISSONADE, G. Législation Comparée des Droits du Conjoint Survivant. Revue de législation ancienne \& moderne française et étrangère, v. 3, p. 643 et seq., 1873.

${ }^{21}$ Sobre as opções doutrinais e o método de Boissonade, JAMIN, Christophe. Boissonade et son temps. Archives de philosophie de droit, n. 44, p. 285 et seq., 2000; KOBAYASHI, Masako. French Legal Advisor in Meiji Japan (1873-1895): Gustave Émile Boissonade de Fontarabie. Tese, University of Hawaii, 1996; SOCIETÉ DE LÉGISLATION COMPARÉE. Boissonade et la réception du droit français au Japon (Colóquio). Paris : Societé de législation comparée, 1991, reproduzido em Revue Internationale de droit comparé, v. 43, n. 2, p. 327-439, abr.-jun. 1991; OKUBO, Yasuo. Gustave Boissonade, père français du droit japonais moderne (1825-1910). Revue historique de droit français et étranger (1922-), v. 59, n. 1, p. 29-54, 1981.

${ }^{22}$ SOLEIL, Sylvain. Manéga en Bessarabie, Bello au Chili et Boissonade au Japon. Trois réformateurs du XIXe siècle face au modèle juridique français. Historia et Ius, n. 3, p. 1-19, 2013.

${ }^{23}$ YNTEMA, Hessel E. Le droit comparé et l'humanisme. Discours inaugural du 4 août 1958 (Ve Congrès international de droit comparé de Bruxelles, 1958). Revue internationale de droit comparé, v. 10, n. 4, p. 693700, 1958. p. 698.
} 


\section{COMPARAR PARA OFERECER OS DADOS, EXPOR AS LEGISLAÇÕES,}

\section{CLASSIFICAR}

O autor do século XIX, por um procedimento didático e científico de compartilhamento de conhecimentos, pode ter como principal motivação apresentar ao seu leitor dados jurídicos estrangeiros (estudos justapostos de legislação, tabelas de concordâncias, traduções, monografias), até mesmo tentativas de classificação. Abordamos aqui uma questão disputada na virada dos séculos XIX-XX e até os dias de hoje: o autor que apresenta elementos da legislação estrangeira faz propriamente uma comparação jurídica? Quando ele justapõe os dados, quando traduz e comenta textos, podemos dizer que ele está comparando direitos? Pode haver aí relação entre estudo dos direitos estrangeiros e comparação dos direitos? No momento em que a doutrina questionará sobre o que é direito comparado e o que não é, com frequência fechará a porta para essa abordagem. Em 1894, Frantz von Liszt indica, por exemplo: "não é legislação comparada o que muitas vezes se aprova como tal, a saber: o tratado sobre um direito nacional isolado, por mais distante que ele seja"24. Em 1900, Raymond Saleilles se lamenta diante das obras que são apenas "estudos de legislação estrangeira, sem que a comparação que daí emerge fosse mais do que uma simples aproximação, ou uma simples justaposição de instituições, e sem que haja a menor tentativa de apresentar uma análise das leis científicas que devem presidir esta comparação, ou este tipo de penetração recíproca" ${ }^{25}$. Em 1932, para Walther Hug isto é "uma simples prévia ao direito comparado" 26 . Para entender o que está em jogo na controvérsia - e fazer justiça aos autores das tabelas de concordâncias, traduções e monografias - é necessário, em primeiro lugar, identificar suas maneiras de proceder, antes de restituir suas motivações (“mobiles") no contexto mais amplo de expectativas de seus leitores.

O primeiro método é aquele dos estudos justapostos de legislação, por exemplo, usado por Zuppetta no primeiro volume de seu Corso completo di legislazione penale comparata (1852) em três volumes. O autor distingue, numa longa introdução, o que denomina "a metafísica da ciência das leis penais" que estuda, em geral, os raciocínios que conduzem a

\footnotetext{
${ }^{24}$ VON LISZT, Franz. La législation pénale comparée publiée par l'Union internationale de droit pénal. Berlim, Paris, Roma, Lisboa: [s. n.], 1894, v. 1, p. xix.

${ }^{25}$ SALEILLES, R. Rapport présenté à la commission d'organisation sur l'utilité, le but et le programme du congrès, 1900. In: Congrès international de droit comparé (1900). Paris: Sirey, 1905, p. 13.

${ }^{26}$ HUG, Walther. The History of Comparative Law. Harvard Law Review, v. 45, n. 6, p. 1027-1070, 1932, p. 1028 , note 2 .
} 
prever os crimes e as penas - o que ele denomina "a ciência particular das leis penais", que se interessa pelos raciocínios que, em particular, conduzam a prever os crimes e as penas ${ }^{27}$. Em seguida, tema após tema (por exemplo: as leis punitivas, no que diz respeito à sua definição, sua natureza, seu autor etc.), Zuppetta apresenta o direito romano e as legislações francesa, piemontesa, austríaca, pontifical, de Modena, de Parma, de Toscana, das Duas Sicílias etc.

O segundo método é aquele das tabelas de concordância, por exemplo, utilizadas três vezes por Fortuné Anthoine de Saint-Joseph a propósito das legislações civis, comerciais e hipotecárias. $\mathrm{O}$ autor, em sua Concordance entre les codes civils étrangers et le Code Napoléon (1840), organiza tabelas comparativas (para cada legislação, uma coluna) nas quais se sucedem, em relação aos artigos do Código Napoleão, os artigos das legislações austríaca, prussiana, da Louisiana, da Sardenha, bávara, holandesa, do cantão de Vaud, do Reino das Duas Sicílias etc. O autor justifica seu trabalho ${ }^{28}$ :

[p]ensamos que estávamos a fazer algo útil ao reproduzir neste livro as disposições
das leis estrangeiras de forma analítica, a única, a nosso ver, que nos permite
penetrar e compreender a substância de toda uma legislação. Aproximando essas leis
aos diversos artigos do Código Napoleão, submetendo-as, para auxiliar a pesquisa e
a inteligência, à divisão adotada neste Código, pensamos que seria mais fácil para o
leitor apreender as nuances que reúnem ou diferenciam as diversas legislações da
Europa, e assim pressentir as melhorias que se pode esperar por toda parte e em
todos os países.

Um terceiro método é aquele das legislações traduzidas, artigo por artigo, precedidas de uma introdução e acompanhadas de notas explicativas. Mencionemos aqui, por exemplo, o norte-americano Duponceaux que, após fornecer uma visão geral da lei de falências francesa na Bankrupt Law of America compared with the Bankrupt Law of England (1801) de Cooper, publica traduções em língua inglesa do código de comércio (1807) e do código penal (1810) francês na American Review of History and Politics de 181129. Citemos, o Code des lois des Anglais ; ou Digeste des principes du droit anglais présentés selon l'ordre du Code Napoléon (1839), publicado pelo advogado inglês George Blaxland. Este conta que, no tempo em que negociava no continente, teve que suportar a zombaria de franceses e holandeses sobre o direito inglês: comparado ao Código Civil e ao Código Comercial francês que, de um simples

\footnotetext{
${ }^{27}$ ZUPETTA, L. Corso completo di legislazione penale comparata ossia commenti storico-filosofico-legali, al codice penale ed al codice di procedura criminale degli stati sardi e di tutti gli altri stati d'Italia, messi in comparazione fra di loro. Turin: Tipografia economica, 1852. 3v. t. 1, p. 25 s.

${ }^{28}$ SAINT-JOSEPH, Fortuné Anthoine de. Concordance entre les codes civils étrangers et le code Napoléon. Paris, Leipzig: Hingray, 1840, p. i.

${ }^{29}$ Sobre essas publicações, NADELMANN, Kurt H. Pierre-Etienne Du Ponceau. Revue internationale de droit comparé, v. 5, n. 2, p. 284-290, 1953, p. 285.
} 
relance, permitiam redigir um contrato ou conhecer o regime jurídico de tal ou qual bem, o direito inglês não permitia nada disto. Tratava-se de um amontoado confuso de decisões, tratados, leis, enfim, um direito indigesto e misterioso ${ }^{30}$. Ora, acrescenta, tudo o que possa facilitar o conhecimento do direito de outros países é muito útil para a Inglaterra, a primeira nação mercante do mundo; depois de um quarto de século de paz, as trocas são universais, notadamente com os franceses. Sua motivação ("mobile"), ele explica, é, portanto, fornecer aos ingleses não apenas o código francês em uma tradução inglesa, mas também o direito inglês em uma formulação francesa. Além disto, a obra é apresentada em três partes distintas. Em primeiro lugar, 180 páginas de história comparativa do direito entre a França e a Inglaterra. Em segundo lugar, 300 páginas do direito inglês exposto, artigo por artigo, seguindo a ordem e a forma do código civil francês (artigos 1 a 1369). Para cada artigo, o autor procura expressar a regra inglesa à la française, ou seja, de forma sintética e em uma linguagem moderna; e, na margem, os números dos artigos franceses correspondentes e, em notas, as referências às fontes de direito inglês (autores, statute e common law). Em terceiro lugar, a tradução para o inglês do Código Napoleão, tendo, às vezes entre colchetes, os termos franceses traduzidos e uma referência à regra inglesa ${ }^{31}$ :

841. Every person, even a relation of the deceased, not being in the order of succession (qui n'est pas son successible), and to whom a coheir shall have ceded his claim upon the succession, may be excluded from the division, either by all the coheirs, or by one only, on reimbursing him the price of such cession.

See parallel but dissimilar English law, p. 393. [...]

1146. Damages and interest (dommages et interets*) are only due when the debtor is in arrear in fulfilling his obligation; except nevertheless when the thing which the debtor has bound himself to give or to do cannot be given or done buth within a certain time, which he has suffered to pass by. $\dagger$

* These termes together most closely correspond with that of damages in the English law.

$\dagger$ See parallel principle of English law, p. 447.

Um quarto método - o mais frequente - é aquele da monografia dedicada a uma legislação estrangeira, um mecanismo ou uma instituição específica. O objetivo é fazer conhecer o seu conteúdo com uma comparação, de forma indireta, do direito exposto com o

\footnotetext{
${ }^{30}$ BLAXLAND, George. Codex Legum Anglicanarum: Or, A Digest of Principles of English Law; Arranged in the Order of the Code Napoleon. Londres: Henry Butterworth, 1839, p. iii.

${ }^{31}$ BLAXLAND, George. Codex Legum Anglicanarum: Or, A Digest of Principles of English Law; Arranged in the Order of the Code Napoleon. Londres: Henry Butterworth, 1839, Appendix, p. 98; p. 132 (“art. 841. Qualquer pessoa, mesmo parente do falecido, que não seja seu sucessor, e a quem um co-herdeiro tenha cedido seu direito à sucessão, pode ser excluída da partilha, seja por todos os co-herdeiros ou por apenas um, reembolsando-lhe o preço da cessão"; "art. 1146. Os danos e indenizações só são devidos quando o devedor estiver inadimplente com sua obrigação, exceto, todavia, quando a coisa que o devedor estava obrigado de dar ou de fazer só poderia ser dada ou feita dentro de um certo tempo que ele deixou passar").
} 
direito do leitor. Tomemos o exemplo da Académie de législation de Toulouse, uma academia jurídica provincial onde membros ordinários, correspondentes e jurisconsultos estrangeiros leem, discutem e publicam obras a partir de 1851. O estudo do jurista de Modena, Lodovico Bosellini, sobre a organização judiciária italiana (1859), o estudo do professor de São Petersburgo, Constantin de Brochoki, a respeito da legislação russa sobre duelos (1863) ou o estudo do magistrado francês sediado em Alexandria, Maurice Bellet, sobre tribunais mistos egípcios (1879) correspondem a este projeto $^{32}$. Embora a tendência geral seja, de preferência, extrair da comparação conclusões em termos de vantagens e inconvenientes respectivos (ver supra - comparar para criticar, promover, reformar), esses três autores não se aventuram a propor conclusões gerais; eles se contentam em explicar legislações e instituições estrangeiras.

Estudos justapostos de legislações, concordâncias, traduções, monografias - qualquer que seja o método escolhido - a principal motivação ("mobile") do autor é oferecer ao leitor elementos a serem explorados, mais do que elementos já explorados. A rigor, não se trata, portanto, de direito comparado no sentido em que entenderão mais tarde Liszt, Saleilles ou Hug. Trata-se, entretanto, de uma comparação jurídica indireta e implícita, se recolocarmos as coisas no contexto mais amplo do projeto editorial que diz respeito tanto ao leitor quanto ao autor e seu editor ou sua revista. Todos esses dados são concebidos, com efeito, em função das expectativas do leitor. O autor (en amont) antecipa essas expectativas fazendo um trabalho de comparação invisível quando procede à escolha dos textos, quando desenvolve sua apresentação, quando faz referência ao direito do leitor, quando faz observações sobre as palavras traduzidas, quando introduz o seu propósito. Os leitores (en aval) podem explorar esses dados jurídicos, em particular para fins comparativos: 1) os práticos que buscam soluções para prevenir ou dirimir conflitos de leis, pois, para eles, não há soluções sem dados estrangeiros, oficiais e precisos (ver infra - comparar para indicar como reger e julgar); 2) os autores que se apaixonam pela comparação de direitos, porque, para estes, não há comparação sem matéria e não há matéria sem dados (ver infra - comparar para alimentar teorias históricas - comparar para unificar o direito); 3) os reformadores em busca de modelos estrangeiros, para neles se inspirar ou se afastar (ver supra-comparar para criticar, promover, reformar). As obras de Anthoine de Saint-Joseph são, portanto, utilizadas no

\footnotetext{
${ }^{32}$ BOYER, Pierre-Louis. Un cercle intellectuel au coeur de l'évolution de la doctrine juridique: l'Académie de législation de Toulouse (1851-1958). Paris: LGDJ, 2014. (Bibliothèque d'histoire du droit et droit romain, tome 27), p. 390 s.
} 
exterior, especialmente em países sem doutrina. Os reformadores descobrem aí, de forma clara e numa linguagem compartilhada, os modelos de que precisam para refletir, avaliar, comparar e fazer escolhas legislativas ${ }^{33}$. Como tal, podemos tomar o exemplo de Andrés Bello, o famoso reformador chileno. Ele utiliza a Concordance entre les codes civils étrangers et le Code Napoléon de Anthoine de Saint-Joseph a qual, em seus vários projetos (1841-1845, 1846-1847, 1853, 1855), faz referências por abreviaturas: C.A. (Código austríaco), C.F. (código francês), C.L. (código de Louisiana), C.D.S. (código das Duas Sicílias), C.P. (código prussiano), C.S. (código da Sardenha) ${ }^{34}$.

Na verdade, nossos autores às vezes antecipam suas necessidades. Blaxland, com sua tradução do Código Napoleão e sua apresentação do direito inglês segundo a ordem do Código Napoleão, explica querer - em uma espécie de jogo duplo - permitir que seu leitor participe da modernização do direito inglês e, ao mesmo tempo, o defender contra ataques injustos dos codificacionists ${ }^{35}$. Quanto à Anthoine de Saint-Joseph, ele se pergunta no Avertissement de sua Concordance: "Não teríamos nos desviado deste trabalho por sua aridez e pelo temor de encontrar apenas um pequeno número de leitores?"36. Não, acredita ele, porque muitos leitores terão interesse em consultar a obra: quem quiser penetrar a substância das legislações e fazer do direito uma ciência que se apoia na comparação; aquele que deseja melhorar a legislação e "conduzir ao aperfeiçoamento progressivo dos códigos"; o legislador, o magistrado e o jurisconsulto que meditam, mas também o historiador, o literato, o político que se interessam pelas semelhanças e diferenças de costumes e caracteres entre os povos.

\footnotetext{
${ }^{33}$ SOLEIL, Sylvain. Le modèle juridique français dans le monde: une ambition, une expansion, XVIe-XIXe siècle. Paris: IRJS Éditions, 2014. (Les voies du droit), p. 357 s.

${ }^{34}$ Sobre o recurso de Bello aos diversos modelos estrangeiros, GUZMÁN BRITO, A. La Formación del sistema general del Código Civil de Chile y los sistemas de los códigos existentes hacia 1852. In: MARTINIC, M.; TAPIA, M. (Orgs.). Sesquicentenario Del Codigo Civil de Andres Bello: Pasado, Presente Y Futuro de La Codificacion. Paris: LexisNexis, 2005, p. 123 e ss.; ARANEDA, C. El derecho canónico en el Código Civil de la República de Chile. In: MARTINIC, M.; TAPIA, M. (Orgs.). Sesquicentenario Del Codigo Civil de Andres Bello: Pasado, Presente Y Futuro de La Codificacion. Paris: LexisNexis, 2005, p. 203 et ss.; MIROW, M. C. Andrés Bello, sucesiones, y el Código Civil francés de 1804. In: MARTINIC, M.; TAPIA, M. (Orgs.). Sesquicentenario Del Codigo Civil de Andres Bello: Pasado, Presente Y Futuro de La Codificacion. Paris: LexisNexis, 2005, p. 177 et ss.; BRAVO-LIRA, B. Derecho romano y codificación civil. De los dos grandes modelos euorpeos, austriaco (1797) y Francés (1804), al Código de Chile (1855). In: MARTINIC, M.; TAPIA, M. (Orgs.). Sesquicentenario del Codigo Civil de Andres Bello: Pasado, Presente Y Futuro de La Codificacion. Paris: LexisNexis, 2005, p. 171 s.

${ }^{35}$ SOLEIL, Sylvain. In the Order of the Code Napoleon. Les carences du droit anglais au révélateur du modèle juridique français (1820-1840). In: GASNIER, F.; BLANCHARD, C. (Orgs.). Aux confins du droit, hommage amical à Xavier Martin. Poitiers: LGDJ, Presses Universitaires de Poitiers, 2015, p. 377-397.

${ }^{36}$ SAINT-JOSEPH, Fortuné Anthoine de. Concordance entre les codes civils étrangers et le code Napoléon. Paris, Leipzig: Hingray, 1840, p. i.
} 
Numa abordagem didática e científica semelhante, porém mais ampla, o autor também pode propor uma abordagem savante das semelhanças e diferenças e, a partir daí, uma classificação por sistemas jurídicos. Trata-se, então, em termos de comparações mais ou menos bem acabadas, de modelização, isto é, de simplificar a complexidade de cada sistema jurídico examinado, a fim de os reduzir em algumas características maiores e classificá-los por categorias, um pouco como, na mesma época, o alemão August Schleicher classifica as línguas, seguindo o método da gramática comparada, ou como Georges Cuvier classifica as espécies extintas e Alexander von Humboldt e Charles Darwin classificam as espécies vivas, seguindo o método de anatomia comparativa ${ }^{37}$. Tomemos dois exemplos franceses em matéria administrativa e comercial.

De 1862 a 1868, o publicista Anselme Batbie publica seu Traité de droit public, em sete volumes, que merece ser citado na íntegra ${ }^{38}$. Traité théorique et pratique de droit public et administratif contenant l'examen de la doctrine et de la jurisprudence ; la comparaison de notre législation avec les lois politiques et administratives de l'Angleterre, des États-Unis, de la Belgique, de la Hollande, des principaux États de l'Allemagne et de l'Espagne ; la comparaison de nos institutions actuelles avec celles de la France avant 1789 ; et des notions sur les sciences auxiliaires de l'administration, l'économie politique et la statistique. Este, matéria por matéria, compara o estado atual do direito administrativo francês com o direito anterior e as outras legislações. No prefácio, ele adverte e justifica seu método ${ }^{39}$ :

\begin{abstract}
Uma lacuna que se encontra em todos os tratados que antecederam o nosso, sem distinção, é o estudo da legislação estrangeira, ou o direito comparado. Procuramos preenchê-la, estudando, sobre cada matéria, as principais legislações. Para fazer essa comparação da melhor maneira possível, adotamos três pontos de vista diferentes: $1^{\circ}$ os povos cuja administração mais difere da nossa, isto é, a Inglaterra e os Estados Unidos da América do Norte ; $2^{\circ}$ aqueles que mais nos imitaram e cujas instituições estão mais próximas de seu modelo: nesta categoria se encontra a Espanha; $3^{\circ}$ os povos que ocupam uma espécie de meio entre as nossas instituições e as da Inglaterra, que derivam tanto da nossa regularidade administrativa como do autogoverno além-Mancha, a Bélgica, a Holanda e alguns Estados da Alemanha.
\end{abstract}

\footnotetext{
${ }^{37}$ Sobre essas disciplinas e seus métodos, DESMET, Piet. La linguistique naturaliste en France (1867-1922): nature, origine et évolution du langage. Leuven: Peeters, 1996, p. 47 s. ; SCHMITT, Stéphane. Aux origines de la biologie moderne: l'anatomie comparée d'Aristote à la théorie de l'évolution. Paris: Belin, 2006. (Collection Belin sup Histoire des sciences-biologie), p. 151 s. ; p. 345 s.

${ }^{38}$ Sobre Batbie e sua contribuição à comparação, TOUZEIL-DIVINA, Mathieu. La doctrine publiciste, 1800 1880: éléments de patristique administrative. Paris: Éd. La Mémoire du Droit, 2009, p. 177 et seq., p. 254 et seq.; FALÉLAVAKI, Yannick. L'histoire d'une conversion: la doctrine française du XIXe siècle et le recours à la comparaison juridique. Tese, Rennes 1, Rennes, 2016,, p. 177 et. seq., p. 292 et, seq.

${ }^{39}$ BATBIE, Anselme. Traité théorique et pratique de droit public et administratif. Paris: Cotillon, 1862, t. i, p. 5-6. A abordagem comparatista de Batbie nos foi indicada por Yannick Falelavaki. Que ele seja agradecido.
} 
Assim, faz, por exemplo, no que diz respeito à organização das comunas nos Estados Unidos, na Inglaterra, na Itália, Bélgica, Holanda, Espanha, Alemanha, Áustria, Hungria e Rússia (no volume IV da edição de 1885, p. 77 e s.) ou a propósito da expropriação e obras públicas na Inglaterra, Rússia, Espanha, Bélgica, Itália, Alemanha, Suíça e Estados Unidos (no volume VII da edição de 1885, p. 252 e s.).

De forma bastante semelhante, o comercialista Charles Lyon-Caen publica, primeiro sob a forma de artigo no Journal de droit international privé (1876) e depois na forma de livro (1881), uma Tableau des lois commerciales en vigueur dans les principaux États de l'Europe et de l'Amérique ${ }^{40}$. Ele se explica ${ }^{41}$.

Ao comparar conjuntamente as leis comerciais dos diferentes povos, constata-se entre elas divergências bastante numerosas. Mas essas divergências são muito menos importantes e em muito menos número do que as que existem entre as leis civis. Em todos os países, a legislação comercial nos apresenta as mesmas instituições, sociedades por ações, os efeitos comerciais, falências, seguros, etc.; e frequentemente há uma semelhança marcante entre as maneiras pelas quais essas instituições são reguladas.

Lyon-Caen procurar examinar as causas dessas semelhanças: as leis comerciais, ele explica, são menos variáveis do que as leis civis; eles têm uma origem comum (os costumes dos comerciantes); o código de comércio francês de 1807 serviu de modelo à maioria dos códigos estrangeiros. De modo que o autor começa apresentando o código francês antes, em 30 páginas, de apresentar a estruturação das legislações comerciais de uns quarenta países ${ }^{42}$ :

Para apresentar a tabela das leis comerciais atuais nos principais Estados para além da França, vamos dividir esses países em três grandes classes:

I. Países com Códigos de comércio, que foram redigidos sob a influência direta do Código de comércio francês [Itália, Holanda, Bélgica, Espanha, Portugal, Grécia, Turquia, Egito e Romênia],

II. Países com Códigos de comércio que não derivam totalmente do Código francês, III. Países sem Código de comércio [Grã-Bretanha, Estados Unidos e os países escandinavos].

Nestes autores, a comparação segue um motivo ("mobile”) didático e científico, até mesmo sistemático. Trata-se de fornecer dados e expor as legislações estrangeiras (Zupetta, Blaxland, Anthoine de Saint-Joseph, Bosellini ou Brochoki), de descrever as peculiaridades,

\footnotetext{
${ }^{40}$ Sobre Lyon-Caen e sua contribuição à comparação, CIANCIO, C. Les congrès internationaux de droit commercial : un réseau de commercialistes européens à la recherche d'un droit uniforme. In: LE YONCOURT, Thiphaine (Org.). L'Idée de fonds juridique commun dans l'Europe du XIXe siècle: les modèles, les réformateurs, les réseaux. Rennes: Presses universitaires de Rennes, 2014. (Collection "L'univers des normes"), p. $253 \mathrm{~s}$.

${ }^{41}$ LYON-CAEN, Charles. Tableau des lois commerciales en vigueur dans les principaux états de l'Europe et de l'Amérique. Paris: A. Cotillon, 1881, p. 5.

${ }^{42}$ Ibidem, p. 12.
} 
"estudar" as legislações estrangeiras (Batbie) ou "apresentar a tabela" das legislações estrangeiras (Lyon-Caen), e então ordenar o conhecimento e catalogá-lo em função de critérios selecionados pelo autor.

\section{COMPARAR PARA INDICAR COMO REGER E JULGAR}

O autor do século XIX pode ter como principal motivo guiar a atividade concreta de administradores e práticos, e isto em um duplo contexto colonial e internacional. No plano internacional, trata-se de livros que estudam e comparam diversas legislações, a fim de indicar aos práticos como prevenir ou resolver eventuais conflitos de leis ${ }^{43}$. É nessa lógica que Story, Fœlix e Mancini publicam seus tratados ${ }^{44}$. Joseph Story - após seus estudos de direito em Harvard, ingressa na agremiação dos advogados de Salem em 1801 e é nomeado juiz da corte suprema dos Estados Unidos em 1811 - publica seus Commentaries of the conflict of laws, foreign and domestic (1834). Ele explica querer oferecer à profissão e ao público um exame dos princípios que norteiam os conflitos de leis. Ele constata que a doutrina de common law acusa, neste ponto, um considerável atraso com relação aos juristas da Europa continental ${ }^{45}$. Ora, diz ele, o problema é o mesmo de sempre ${ }^{46}$.

A terra desde muito tempo foi dividida em nações distintas, habitando diferentes territórios, falando diferentes línguas, engajados em diferentes atividades e vinculados a diferentes formas de governo. Era natural, em tais circunstâncias, que pudesse haver grande variedade em suas instituições, costumes, leis e políticas. [...] No entanto, mesmo em virtude dessas circunstâncias, às vezes surgiram problemas, devido as relações de uns com os outros, quanto à aplicação das leis de uma nação em relação aos direitos e recursos das partes em tribunais nacionais, em particular quando, de uma maneira ou de outra, estavam vinculados ou dependiam de transações estrangeiras. [tradução nossa]

\footnotetext{
${ }^{43}$ ANCEL, Bertrand. Le droit international privé comparé. Paris: Éd. Panthéon-Assas, 2007, p. 19 et seq.; HALPÉRIN, Jean-Louis. Entre nationalisme juridique et communauté de droit. 1re éd. Paris: Presses universitaires de France, 1999. (Les voies du droit); JAYME, Erik. Identité culturelle et intégration: le droit international privé postmoderne. Recueil de cours de l'Académie de droit international. La Haye: Martinus Nijhoff Publishers, 1995, p. 39 s.; SCHNYDER, Anton. Wirtschaftskollisionsrecht. Zurich: Schulthess-Schaffer, 1990, p. 9 s.

${ }^{44}$ FOELIX, Jean-Jacques-Gaspard. Traité de droit international privé. Des conflits de lois de différentes nations en matière de droit privé. Paris: Joubert, 1843; MANCINI, Pasquale Stanislao. Della nazionalità come fondamento del diritto delle genti. prelezione al corso di diritto internazionale e marittimo. Turin: Tipografia Eredi Botta, 1851.

${ }^{45}$ Sobre o trabalho fundador de Story, ver SYMEONIDES, Symeon C. American private international law. Austin, Boston, Chicago, New York, Wolters: Kluwer, 2008, p. 108 et seq.

${ }^{46}$ STORY, Joseph. Commentaries of the conflict of laws, foreign and domestic, in regard to contracts, rights, and remedies, and especially in regard to marriages, divorces, wills, successions, and judgments. Boston: Little and Brown, 1834, p. i.
} 
Após um pequeno afresco histórico (capítulo 1, p. 1 et seq.), Story estuda as máximas gerais do direito internacional (capítulo 2, p. 19 et seq.), antes de examinar a aplicação e o efeito das leis estrangeiras no que diz respeito ao domicílio, o estatuto das pessoas, dos contratos, da propriedade, das sucessões etc. Para indicar as melhores soluções, Story detalha e compara os diversos regimes jurídicos, essencialmente a partir de jurisconsultos franceses (em menor medida, autores romanos, ingleses, americanos, alemães e holandeses) e casos julgados pelos tribunais americanos e europeus, inglês e escocês.

No plano colonial, trata-se de obras que estudam e comparam as diversas legislações, a fim de indicar aos práticos como administrar os territórios e julgar os litígios. As descobertas, as fundações, as conquistas e reconquistas efetuadas pelas potências europeias em todo o mundo colocaram, de fato, as autoridades oficiais diante de uma grande diversidade jurídica. É necessário, por um lado, zelar pela ordem pública e impor gradativamente o poder colonial pelo direito e a justiça, por outro, preservar parcialmente as leis e os costumes locais. $\mathrm{O}$ francês, o inglês, o espanhol, o belga ou o alemão irão, portanto, experimentar vários modelos cuja apresentação binária Indirect Rule anglais/Domination directe française não reflete fielmente com precisão ${ }^{47}$. $\mathrm{Na}$ realidade, as abordagens coloniais são diversas, às vezes misturadas umas às outras, e dependem dos lugares, períodos e dos agentes. No entanto, elas têm um ponto em comum: a necessidade de conhecer e comparar as regras jurídicas umas às outras.

Tomemos aqui o exemplo do império britânico. Com as idas e vindas de juízes e governadores no império vitoriano, surge uma necessidade constante de atualização. Trata-se de conhecer, compreender e aplicar ora o direito local, ora o direito espanhol, ora o direito francês do Ancien Régime (os costumes de Paris), ora o direito napoleônico, ora o direito romano-holandês etc. Daí a necessidade prática de identificar as regras aplicáveis ${ }^{48}$. É com

\footnotetext{
${ }^{47}$ DURAND, Bernard. Introduction historique au droit colonial. Paris: Economica, 2015. (Corpus. Histoire du droit), p. 343 et seq.; SCHLOTTAU, Ralf. Deutsche Kolonialrechtspflege: Strafrecht und Strafmacht in den deutschen Schutzgebieten 1884 bis 1914. Frankfurt am Main: Lang, 2007. (Rechtshistorische Reihe); DORSETT, Shaunnagh; MCLAREN, John D (Orgs.). Legal histories of the British Empire: laws, engagements and legacies. New-York: Routledge, 2014; LUIS, Jean-Philippe (Org.). L'État dans ses colonies: Les administrateurs de l'Empire espagnol au XIXe siècle. Madrid: Ed. de la Casa de Velásquez, 2015.

${ }^{48}$ DEN OTTER, Sandra. 'A legislating empire': Victorian political theorists, codes of law, and empire. In: BELL, Duncan (Org.). Victorian Visions of Global Order: Empire and International Relations in NineteenthCentury Political Thought. Cambridge: Cambridge University Press, 2007, p. 89-112. (Ideas in Context); KIRKBY, Diane Elizabeth; COLEBORNE, Catharine (Orgs.). Law, history, colonialism: the reach of empire. Manchester: Manchester University Press, 2001. (Studies in imperialism); FOSTER, Hamar; BUCK, A. R; BERGER, Benjamin L (Orgs.). The grand experiment: law and legal culture in British settler societies. Vancouver: UBC Press, 2008.
} 
esse espírito que Burge publica os quatro volumes de seus Commentaries on Colonial and Foreign Laws, generaly, and in their conflict with each other, and with the law of England (1838). Jurista trabalhando para a administração colonial, ele se torna procurador-geral da Jamaica em 1819. Ele explica em sua dedicatória à Henry Langdale ${ }^{49}$ :

Nesta obra, que Vossa Senhoria me autorizou a lhe dedicar, meu objetivo foi de coletar (bring together) esses diversos sistemas de direito colonial e estrangeiro, que constituem parte considerável do direito regido pelo tribunal supremo de apelação do império colonial britânico e que são frequentemente objeto de questões judiciárias perante outros tribunais desse país. Eles são apresentados em relação ao direito inglês, e quando eles entram em conflito com esse direito, ou uns com os outros, me esforcei para estabelecer e indicar os princípios sobre os quais a seleção de um desses direitos poderia ser feita. [tradução nossa]

Matéria por matéria (estatutos, capacidades e incapacidades, domicílio, bens, contratos, sucessões etc.), Burge propõe definições, apresenta os diversos regimes jurídicos e seus fundamentos conceituais, depois, território por território, ele não apresenta simplesmente dados (ver infra-oferecer os dados jurídicos, expor as legislações, classificar), mas também as linhas diretivas e os conselhos para fazer escolhas sensatas. Em outras palavras, o autor já explorou os dados em uma lógica funcional. O juiz e o administrador colonial podem: 1) acolher a diversidade jurídica do império, 2) conhecer as semelhanças e as diferenças entre as regras de origens diversas, 3 ) recorrer à regra aplicável ${ }^{50}$ :

Existem grandes conflitos entre os diferentes códigos jurídicos examinados neste trabalho, em função da maneira como se trata esses variados temas. Frequentemente, torna-se essencial que os juízes saibam como selecionar um desses direitos em conflito. Os princípios sobre os quais a seleção deve ser feita constituem um importante ramo do direito. Isso constitui uma parte desse trabalho. O exame desses princípios segue o resumo dos direitos, cada vez em que a oportunidade de sua aplicação for assegurada, seja por uma lacuna entre esses direitos, seja pela natureza do objeto sobre a qual existe a lacuna. [tradução nossa]

Veremos como funciona. Com relação ao estatuto jurídico dos escravos nas diferentes colônias, ele questiona, no tomo II, sobre a dupla categoria de móveis/imóveis (civil law) e propriedade real/propriedade pessoal (commom law) ${ }^{51}$. Para operar de maneira compreensível, ele distingue, em duas seções, a dupla categoria conforme os bens estudados sejam corpóreos (terras, edifícios, animais etc.) ou incorpóreos (direitos, heranças, hipotecas etc.). Sua preocupação é explicar como é regido os bens em cada um dos sistemas inglês, americano,

\footnotetext{
${ }^{49}$ BURGE, William. Commentaries on Colonial and Foreign Laws generally, and in their conflict with each other, and with the law of England. Londres: Saunders and Benning, 1838. 4v. t. i, p. i-ii.

${ }^{50}$ Ibid., t. I, p. x.

${ }^{51}$ Ibid., t. II, p. 6.
} 
escocês, francês (os costumes de Paris, depois o Código Napoleão), holandês e espanhol. É após examinar as questões de móveis e imóveis por destinação que ele detalha, no parágrafo XII, o estatuto dos escravos. Em primeiro lugar, o princípio: “embora sejam móveis per se e ex natura sua, todavia, si fundo adscripti sint, são reputados pelo direito civil como parte integrante da fazenda e da propriedade imóvel". Em seguida, volta-se para o exame das situações locais com a preocupação de orientar a escolha entre chattel ou real estate, de acordo com as regras que regem os bens, a venda, as dívidas, as sucessões: na Jamaica, com algumas exceções, os escravos são real estates; em Barbados, Ilhas Virgens, Antígua, Montserrat, São Cristóvão, São Vicente, Tobago e Granada, igualmente são considerados como real estates, exceto a título de pagamento de dívidas; em Nevis, são considerados como chattels com a morte do proprietário - podendo, portanto, ser distribuídos aos filhos, segundo as regras de sucessão em vigor - mas o cônjuge sobrevivente pode os conservar como estates, fornecendo, durante sete anos, aos descendentes do falecido, uma certa soma; em Dominica, Bermuda e Bahamas, eles são sempre reputados chattels; na Guiana Inglesa são chattels, mas não podem ser vendidos separadamente do imóvel; em Trinidad são chattels, mas com opção perante o tribunal; nas colônias francesas, eles são reputados móveis pelo fato do Code Noir de 1685 e do édito de 1786; na Louisiana, eles são móveis por natureza, mas imóveis por fato da lei ${ }^{52}$.

Burge, para chegar a este resultado, comparou cada sistema estrangeiro em relação ao direito inglês (suas fontes, suas formas, seus conteúdos), sublinhou semelhanças e singularidades, guiou a escolha dos administradores e dos juízes. Seus Commentaires são, portanto, mais do que uma coleção de dados e a Law Magazine (1838) sublinha a dupla ambição do autor: o verdadeiro valor da obra não é ter compilado os direitos em vigor nas colônias, mas ter abraçado de uma só vez os diversos sistemas jurídicos sobre os quais esses direitos são fundados e ter dado ao leitor "uma chave-mestra para interiores e repositórios ( $a$ key-pass to the inner recesses and repositories)" "53. The Legal Observer (1838) vai mais além: antes de convidar os agentes coloniais a lerem os Commentaries, ele insiste na contribuição científica da obra ao afirmar que preenche um vazio na Inglaterra (em relação aos trabalhos de direito comparado continentais e norte-americano) e que será de grande ajuda para juristas e

\footnotetext{
52 BURGE, William. Commentaries on Colonial and Foreign Laws generally, and in their conflict with each other, and with the law of England. Londres: Saunders and Benning, 1838. 4v, t. II, p. 24-27.

${ }^{53}$ Law Magazine, fevereiro 1838 - maio 1838, p. 107.
} 
estudantes preocupados em compreender as grandes doutrinas do direito civil ${ }^{54}$. A comparação de direitos em um contexto colonial permite, então, evocar um continente intelectual subjacente, pouco suspeitado pelos comparatistas: o da comparação de direitos por ocasião de viagens.

\section{COMPARAR PARA RELATAR A DIVERSIDADE}

O autor do século XIX pode ter como motivação principal relatar a diversidade ou a semelhança dos sistemas jurídicos, por relatos, comentários ou exemplos, retirados de relatórios de viagens, tabelas de concordâncias, monografias jurídicas etc.

É o caso do jurista que utiliza exemplos estrangeiros para caracterizar o direito de que trata, sem uma abordagem comparativa de fundo. A comparação constitui para ele no máximo um processo retórico ou pedagógico. Tomemos aqui o caso de Rogron. Se escolhemos esse autor, é precisamente porque, em sua obra jurídica, a comparação jurídica não tem nenhum lugar. Este autor publicou códigos explicados destinados a estudantes e profissionais. Esses livros, edições após edições, foram comprados por dezenas de milhares. Eles também foram usados algumas vezes no exterior para conhecer o direito francês (ver supra - comparar para oferecer os dados, expor as legislações, classificar, sobre Andrés Bello no Chile). Ora, nas diversas edições do seu Code civil expliqué, do Code pénal expliqué ou mesmo do seu Code de commerce expliqué, buscar-se-ia em vão uma comparação, por menor que ela seja. Nenhuma palavra sobre o direito inglês, prussiano ou austríaco em relação ao direito francês. Não é, pensa Rogron, o seu propósito, nem a expectativa de seus leitores. A comparação não entra em seu projeto editorial. Ele não tem motivação ("mobile”) para fazer isto. No entanto e isso é excepcional - Rogron compara os direitos por ocasião de seu Code politique, a fim de oferecer os exemplos que irão caracterizar o sistema constitucional francês ${ }^{55}$. Trata-se de mostrar, por incisos, ora uma semelhança, ora uma diferença entre duas regras. Com relação à Forme du gouvernement du roi, Rogron cita o artigo 13 da Carta de 1814: "O rei é o chefe supremo do Estado; ele comanda as forças da terra e do mar etc.”.

Esta disposição [explica ele] certamente dá ao rei o direito de se colocar à frente das forças armadas; mas a conservação do príncipe que importa ao Estado, e o interesse

\footnotetext{
${ }^{54}$ Legal Observer, novembro 1837 - abril 1838, p. 370.

${ }^{55}$ ROGRON, Joseph-André. Les codes français expliqués par leurs motifs. Première partie comprenant les codes politique, civil, de procédure civile, de commerce. Paris: Thorel, 1847, p. 51 et seq.
} 
da liberdade pública, não permitem ao rei buscar, exceto em grandes ocasiões, uma glória inútil: é o princípio recebido na Inglaterra; e não há dúvida que um ministério, na França, que aconselhasse o rei a assumir um comando perigoso, engajaria sua responsabilidade.

Sobre a publicidade dos debates na Câmara, ele destaca que "é de costume na Câmara (e isto deveria ser um direito) dar aos estenógrafos e aos redatores de jornais de tribunas particulares. Na Inglaterra, esse costume não existe; os escritores são confundidos com o público" (p. 74). Sobre a dissolução da Câmara dos deputados (p. 82): "O mesmo costume existe na Inglaterra". Sobre a pena de morte: "Existem países como a Inglaterra e a Prússia, onde nenhuma pena de morte pode ser executada sem antes ter uma assinatura régia. $\mathrm{Na}$ França, a lei nada prescreve a esse respeito [...]". Sobre o júri criminal (p. 100): “ $N a$ Inglaterra, é muito mais antigo". Rogron, neste ponto, aventura-se a ir mais longe ao se questionar: qual é, por maioria ou unanimidade, o melhor método? Mas nada, em todas essas incisões, indica uma verdadeira reflexão comparativa, uma vez que o autor simplesmente tem consciência de que uma comparação permite ao leitor, praticante ou estudante, compreender instantaneamente a regra francesa:

É [a propósito da maioria ou unanimidade] uma questão enorme, tratada em numerosos volumes, mas que irá dividir ainda por muito tempo os homens de Estado e os criminalistas; quanto a nós, acreditamos que a unanimidade do júri dificilmente é possível; quase sempre será mais aparente do que real. É o que ocorre na Inglaterra e nos Estados Unidos, onde existe de direito, mas não de fato, pois a minoria se coloca sempre forçosamente do lado da opinião da maioria, e a partir de então a unanimidade é apenas artificial.

Em um outro registo, convém mencionar o autor, viajante, explorador, descobridor, jurista ou não, que nos dá conta da singularidade do direito e dos costumes de um povo estrangeiro em relação aos seus. Este século de descobertas, expansão e colonização dá lugar a uma grande onda de viagens e concretizações editoriais na forma de relatos ou notas de viagens. É uma moda literária que sucede àquela do século XVIII, que conta comparando, e que compara contando, a fim de reportar ao leitor as diferenças entre aqui e lá e melhor sublinhar certas observações pessoais ${ }^{56}$. Ora, assim como o autor compara o clima, a arquitetura ou a geografia, acontece dele fazer comentários comparativos sobre as instituições, os costumes e leis que se descobre no estrangeiro.

\footnotetext{
${ }^{56}$ Sobre as práticas de viagem e a moda dos diários de viagem no século XIX, VENAYRE, Sylvain. Panorama $d u$ voyage (1780-1920): mots, figures, pratiques. Paris: Les Belles Lettres, 2012. (Histoire); ROUSSELZUAZU, Chantal. La literatura de viaje española del siglo XIX, una tipología. Tese, Textas University, 2005; HOOPER, Glenn; YOUNGS, Tim (Orgs.). Perspectives on travel writing. Aldershot, Burlington: Ashgate, 2004. (Studies in European cultural transition, v. 19); WEBER, A.-G. À beau mentir qui vient de loin: Savants, voyageurs et romanciers au XIX ${ }^{\mathrm{e}}$ siècle. Paris : Champion, 2004.
} 
Tomemos alguns exemplos, antes de medir as consequências. O médico e zoólogo alemão Heinrich Carl von Liechtenstein, em suas Voyages au Cap de Bonne-Espérance et le long des côtes occidentales et méridionales d'Afrique, depuis le cap Negro jusqu'au cap Corrientes (1804), conta, ao longo do caminho, uma infinidade de costumes diferentes. Por exemplo, entre os Betjouanas (Lesoto), onde se trata de poligamia, em comparação com a monogamia dos europeus ${ }^{57}$ :

Na conversa, a mais velha [das duas esposas] mostrou muito julgamento. No assunto sobre o costume dos europeus, de casar com apenas uma mulher, ela observou que esse costume não seria bom para os Betjouanas, entre os quais a guerra reduz muito o número de homens, de modo que há muito mais mulheres.

Achille Poussielgue, com base nas notas de viagem do diplomata francês Alphonse de Bourboulon, publica a Voyage en Chine et en Mongolie de M. de Bourboulon (1866) e trata da justiça e das leis chinesas, em relação àquelas da França - a comparação aqui é feita de forma indireta, quase inconsciente ${ }^{58}$ :

Em todas as localidades, há uma sala de instrução onde o subprefeito que faz sua viagem trimestral deve se informar de tudo o que está acontecendo, julgar as contendas e dar uma lição de moral ao povo; mas esta excelente instituição, que apresenta uma certa analogia com os nossos juízes de paz, caiu em desuso por causa do afrouxamento dos laços governamentais e do descuido dos mandarins. [...] Há na China um grande número de leis espalhadas nos éditos imperiais, em coleções de jurisprudência, em livros canônicos; mas não existe, verdadeiramente, código civil nem penal. Os magistrados têm a mais completa latitude para interpretar a lei, que é de uma grande elasticidade, porque é mal definida.

Os cirurgiões da marinha e botânicos Vieillard e Delplanche, em seu Essai sur la Nouvelle Calédonie (1863), explicam como os reis Kanaks fixam "uma infinidade de proibições" por $t a b u$, em relação aos princípios europeus ${ }^{59}$. O jesuíta belga Pierre-Jean de Smet, em suas Voyages aux montagnes rocheuses et séjour chez les tribus indiennes de l'Orégon (1873) ${ }^{60}$, compara, com aquela do seu país, a organização institucional dos índios de Cabeça-Chata da América do Norte. Já o viajante Victor Verneuil, em suas Aventures au Sénégal (1858), compara a lógica penal francesa àquela dos Trarsas. Por detrás da restituição

\footnotetext{
${ }^{57}$ WALCKENAER, Charles-Athanase. Nouvelle collection des relations de voyage par mer et par terre. Paris: Lefèvre, 1830, t. xviii, p. 160.

${ }^{58}$ POUSSIELGUE, Achille. Voyage en Chine et en Mongolie de M. de Bourboulon. Paris: Hachette, 1866, p. 161-162.

${ }^{59}$ VIEILLARD, Eugène; DEPLANCHE, Emile. Essais sur la Nouvelle-Calédonie. Paris: Librairie Challamel Ainé, 1863 , p. 31 e s.

${ }^{60}$ DE SMET, Pierre Jean. Voyages aux montagnes rocheuses et séjour chez les tribus indiennes de l'Orégon (États-Unis). 2. ed. Paris: Decaux et Cie, 1873, p. 58.
} 
da dramatização, do ritmo do diálogo e do espelhamento dos respectivos valores, podemos detectar uma motivação ("mobile") secundária no autor: defender a personalidade das leis, inclusive em matéria penal ${ }^{61}$ :

É indispensável a apelação dos negros perante nosso tribunal em contestação com os europeus; mas parece-nos que teria sido melhor deixá-los julgar entre si do que submetê-los às nossas leis, que não estão de forma alguma relacionadas com os seus costumes. Além disto, a nossa penalidade não os aflige muito, pois temem apenas o desprezo por seus concidadãos e, por um sentimento nacional fácil de compreender, basta que tenhamos condenado um grande criminoso para que sua tribo lhe renda toda a sua consideração. A magistratura do povo senegalês não usa de prisão nem de guilhotina; seu código é inteiramente religioso. Na sexta-feira, dia três vezes santo, os velhos marabus se reúnem sob uma árvore e julgam os culpados. Alguns são privados do casamento por dois, quatro, oito, dez, vinte anos, dependendo da gravidade de seus crimes; outros, mais culpados, são condenados ao celibato perpétuo e reduzidos à servidão. Só o adultério é punido com a morte.

Um dia, quando estava visitando um acampamento mouro na terra dos Trarsas, cruzando uma praça no centro das tendas, vi uma mulher amarrada ao tronco de uma árvore; ao lado estava um homem afiando o fio de um sabre velho com uma pedra. [...] Aqui está o culpado! gritou meu intérprete. Eles o conduzirão às tendas para que receba a maldição de todos os habitantes, depois entregarão à justa vingança daquele que ele ultrajou.

Com efeito, ouvi o som do tam-tam circular por todo o campo, depois finalmente vi o condenado chegar com as mãos amarradas nas costas. Ele foi seguido apenas por seus guardas; o povo da tribo o desprezava demais para assistir ao seu suplício. Ao vê-lo, o noivo parecia subidamente tomado de uma febre ardente, seus músculos se contraíram, seus olhos brilharam. Ele começa cuspindo na cara do culpado; então, depois de chutá-lo para trás, agarrou-o pelos cabelos, e apoia sua cabeça sobre o joelho e começa a serrar lentamente seu pescoço com o sabre. A decapitação dura mais de meia hora. Nem o carrasco, nem a vítima, nem os assistentes, ninguém pronunciava uma palavra. [...]

Vós sois de uma severidade atroz neste país.

Mas não é o adultério o maior de todos os crimes? gritou o guia em exaltação; se matamos o pai, o irmão ou o amigo de um homem, ele sofrerá menos do que se fosse traído pela esposa.

Muhammad disse: "Quem pega uma ovelha ou um manto pode devolver um manto ou uma ovelha. Mas aquele que rompe os laços sagrados do casamento nunca os renovará; então ele deve ser morto, e aquele que morrer sofrerá menos do que o marido sobrevivendo à sua desonra". Depois disto [conclui Verneuil], leve seu código para o Senegal! Os nativos ficarão felizes em ver você julgar o adultério como uma simples ofensa e condenar os culpados a alguns meses de prisão?

Podemos constatar: nestes projetos editoriais, não se trata de uma comparação de fundo, refletida, assumida, mas de relatar descobertas. No entanto, em sua totalidade, esses relatos mantêm a dupla ideia, em consonância com L'esprit des lois de Montesquieu, de que as regras jurídicas são múltiplas e relativas, e que elas formam um todo em relação com o clima, a religião, o comércio, a guerra, os costumes etc. Esses relatos de viagem desempenham, portanto, um papel no espaço intelectual europeu e norte-americano porque

${ }^{61}$ VERNEUIL, Victor. Mes aventures au Sénégal. Paris, Jaccottet: Bourdilliat et Cie, 1858, p. 61-64. 
seus conteúdos oferecem inúmeros exemplos exploráveis por juristas e antropólogos. "Os antropólogos [observa Cécile Vigor] ainda recorrem, no final do século XIX, aos relatos dos missionários ou mesmo dos naturalistas" "62. No que diz respeito aos juristas, tudo isto servirá, por exemplo, para alimentar as diversas teorias de desenvolvimento do direito por graus ou por imitação (ex.: da vingança privada à justiça pública, da comunidade de bens à propriedade individual, dos costumes à lei, da chefia ao Estado).

\section{COMPARAR PARA ALIMENTAR TEORIAS HISTÓRICAS}

O autor do século XIX pode ter como motivação ("mobile") principal alimentar teorias históricas, econômicas, científicas, filosóficas etc., comparando com a ajuda de obras de segunda mão ou com a ajuda de elementos extraídos, por exemplo, de relatos de viagens (ver supra - comparar para relatar a diversidade) ou dados jurídicos oferecidos por juristas (ver supra - oferecer os dados jurídicos, expor as legislações, classificar), etc. É sobre este ponto que devemos mais uma vez nos focar e lembrar que os juristas não são os únicos a recorrer à comparação jurídica, porque não são os únicos a procurar desvendar os mistérios das origens e evoluções. Melhor ainda: é por se interessarem pelo mesmo assunto que diversos autores tomam emprestados uns dos outros dados comparativos, sejam eles antropológicos, jurídicos, biológicos etc. Um filósofo como Hegel, quando descreve o progresso e a realização do espírito universal por meio do direito abstrato, da moralidade subjetiva e depois da moral objetiva, está inclinado a ver na aparição da família e da agricultura os fundamentos do Estado moderno (Rem. 203), da divisão da sociedade em classes, em Ocidente e Oriente (Rem. 206), as diferenças e semelhanças entre o direito consuetudinário e o direito codificado (Rem. 211) ${ }^{63}$. Um naturalista como Darwin, quando examina, nos seres humanos, o desenvolvimento de instintos sociais e virtudes estritamente sociais, relativiza a universalidade da proibição do incesto com base nos trabalhos de Tylor (costumes da Austrália e América setentrional), e insiste, com base nos trabalhos de Bagehot ou Gerland, na ideia de que as infrações (homicídio, infanticídio, roubo) podem ser considerados como crimes para os membros da tribo e apenas como virtudes para aos estrangeiros (costumes dos

\footnotetext{
62 VIGOUR, Cécile. La comparaison dans les sciences sociales. Paris: La découverte, 2005.

${ }^{63}$ HEGEL, Georg Wilhelm Friedrich. Principes de la philosophie du droit. Trad. A. Kaan. Paris: Gallimard, 1940, p. 231 s. ; KERVÉGAN, Jean-François; MARMASSE, Gilles (Orgs.). Hegel penseur du droit. Paris: CNRS Éditions, 2003; DUBOUCHET, Paul. Philosophie et doctrine du droit chez Kant, Fichte, et Hegel. Paris: L'Harmattan, 2005. (Ouverture philosophique).
} 
índios da América do Norte, os dayaks de Bornéu, os Thugs da Índia) ${ }^{64}$. Quanto a Henry Maine, Gabriel Tarde e Josef Kohler, são juristas e pioneiros da antropologia e da sociologia.

A controvérsia entre eles mostra, aliás, como o recurso à comparação jurídica se efetua no centro de um triângulo história/antropologia/sociologia no qual as fronteiras disciplinares tendem a desaparecer, em favor de uma complementaridade de recursos, de objetivos e métodos. Henry Sumner Maine, depois de estudar direito em Cambridge, torna-se professor e publica o seu famoso Ancien Law. Its connection with early history of society and its relation to modern ideas (1861). No mesmo ano, ingressa no Conselho das Índias como assessor jurídico. Suas viagens investigativas o levaram a descobrir uma organização econômica e jurídica de vilarejo que compartilha certos traços comuns com a organização da propriedade da terra da Alta Idade Média europeia. De volta ao Reino Unido, ele reúne seus dados em seis aulas que ministrará em Oxford, sob o título: Villages Communities of the East and West. Six Lectures delivered at Oxford (1871). Maine explica, inicialmente, com muita seriedade, sua abordagem comparativa ${ }^{65}$ :

\begin{abstract}
De acordo com o entendimento comum, a legislação comparada não pretende lançar nova luz sobre a história do direito. Não é igualmente admitido que ela geralmente tende a esclarecer o lado filosófico ou os princípios. O seu trabalho se limita a escolher dois sistemas jurídicos pertencentes a dois povos diferentes e os comparar sobre qualquer ponto do direito: por exemplo, sobre tal ou qual contrato, ou sobre a respectiva situação dos cônjuges no casamento. [De modo que] os ânimos [esprits] competentes não hesitariam em reconhecer que o objetivo principal, senão o único objeto da legislação comparada, é facilitar a elaboração de leis de um ponto de vista prático. [Por outro lado,] examinaremos um certo número de fenômenos paralelos, com a intenção de estabelecer, se possível, que eles são parcialmente dependentes uns dos outros em uma ordem de sucessão histórica. Acho que poderei afirmar que o método comparativo, já tão fecundo em resultados curiosos, não difere do método histórico em algumas de suas aplicações.
\end{abstract}

Sendo certo de que a motivação ("mobile") de Maine é estabelecer a dependência entre "um certo número de fenômenos paralelos", ele usa um método que consiste em comparar e

\footnotetext{
${ }^{64}$ DARWIN, Charles. La descendance de l'homme et la sélection naturelle (1871). Trad. E. Barbier. Paris: [s. n.], 1891, p. 123 et seq.; sobre o impacto intelectual da teoria sobre a evolutionary legal thought dos juristas europeus e norte-americanos, ELLIOTT, E. Donald. The Evolutionary Tradition in Jurisprudence. Yale Faculty Scholarship Series, 1985; RABBAN, David M. Methodology in legal history: From the history of free speech to the role of history in transatlantic legal thought. In: MUSSON, Anthony; STEBBINGS, Chantal (Orgs.). Making Legal History: Approaches and Methodologies. Cambridge: Cambridge University Press, 2012, p. 88-107.

${ }^{65}$ MAINE, Henry Sumner. Village-communities in the East and West: six lectures delivered at Oxford. London: John Murray, 1871, p. 3-12. Ver MACFARLANE, Alan D. J. Some contributions of Maine to history and anthropology. In: DIAMOND, Alan (Org.). The Victorian Achievement of Sir Henry Maine: A Centennial Reappraisal. Cambridge: Cambridge University Press, 1991, p. 111-142; RABBAN, David M. Law's history: American legal thought and the transatlantic turn to history. Cambridge: Cambridge Univ. Press, 2013. (Cambridge historical studies in American law and society). p. 135 et seq.
} 
aproximar suas próprias observações com as conclusões dos historiadores do direito. Por um lado (lecture 3, p. 65 e s.), Maine sintetiza os trabalhos históricos relativos à organização costumeira de exploração agrícola nos vilarejos da Europa do Oeste. Ele resume os trabalhos de McLennan (Primitive Marriage, 1865), de Lubbock (The Origin of Civilisation and the primitive Condition of Man, 1871), de Freeman (The Historical Geography of Europe, 1881), mas também Morier, Palgrave, Kemble, e sobretudo Von Maurer (Einleitung zur Geschichte der Mark-, Hof-, Dorf-, und Stadtverfassung und der offenttlichen Gewalt, 1854; Geschichte der Dorfverfassung in Deutschland, 1865-1866) que concluíam, com relação à antiga posse agrícola das terras alemães, haver equilíbrio entre a soberania individual dentro do domicílio do dono da terra ("tenancier") e a associação entre donos de terra ("tenanciers") dentro do Marke 66. "Qualquer pessoa [acrescenta Maine] familiarizada com as obras de Palgrave, Kemble e Freeman, não pode ignorar que os mais sábios ("savants") autores que estudaram as antigas formas de propriedade de terras na Inglaterra nos traçam um quadro que não difere sensivelmente do Marke teutônico, como acabei de esboçá-lo com base em Maurer"67. Uma primeira comparação entre historiadores alemães e britânicos oferece, portanto, a Maine um modelo de exploração coletiva das terras (o Marke teutônico) que, por sua vez, servirá de dado para comparação. Por outro lado (lecture $I V$, p. 103 et seq.), ele descreve a organização costumeira da exploração agrícola nas aldeias indígenas e conclui que se trata de uma propriedade coletiva de terras. A partir de então, a comparação entre a propriedade coletiva dos vilarejos do Leste (Índia) e os vilarejos do Oeste (Alemanha, Inglaterra) permite a ele deduzir que em um estágio primitivo, a propriedade do solo foi em todo lugar coletiva, e que o estágio ordinário de desenvolvimento passa, ontem na Europa, amanhã na Índia, pelo feudalismo e depois pela apropriação individual do solo ${ }^{68}$ :

Aquele que estuda as antiguidades jurídicas, logo se convence de que, na maior parte da Europa, o solo pertencia antigamente a grupos proprietários, de mesmo carácter e uma composição substancialmente idêntica àqueles cujos vestígios ainda se podem encontrar em partes da Ásia que são abertas à observação paciente e conscienciosa, se sente imediatamente interessado por aquilo que é, na realidade, o grande problema da história do direito. Trata-se do "processus" pelo qual o modo primitivo de desfrute se converteu em sistema agrário, do qual emergiu imediatamente a organização territorial que reinava sobre todo o Oeste do continente europeu, antes da primeira revolução francesa, e da qual é fácil demonstrar que nossa legislação fundiária descende em linha direta.

\footnotetext{
${ }^{66}$ Sobre esses autores, suas relações e doutrinas, TUORI, Kaius. Lawyers and savages: ancient history and legal realism in the making of legal anthropology. Oxon: Routledge, 2015.

${ }^{67}$ Ibidem, p. 112.

68 Ibid., p. 131.
} 
Este trabalho de comparação jurídica com vistas a alimentar uma teoria histórica encontra eco em um contraditor: Gabriel Tarde. Jurista, Tarde ingressa na magistratura em 1867. A partir de 1887 colabora com a revista Archives d'anthropologie criminelle fundada por Lacassagne e publica em 1890 uma de suas obras mais famosas: Les lois de l'imitation ${ }^{69}$. Ele aí rejeita categoricamente a teoria do desenvolvimento por estágios, na medida em que é fatal e determinista, em favor da teoria do desenvolvimento por imitação ${ }^{70}$ :

\begin{abstract}
Este trabalho de uniformização universal, a que assistimos, revela, de alguma forma, uma orientação comum de diversas sociedades em direção a um mesmo pólo? - De jeito nenhum, pois tem como causa manifesta a submersão da maioria das civilizações originais sob o dilúvio de uma delas, cujo fluxo avança em camadas de imitação cada vez maiores. Para ver até que ponto as civilizações independentes estão longe de tender a convergir espontaneamente, comparemos duas civilizações que chegaram ao seu fim e aí estão repousando [...].
\end{abstract}

A partir de então, Tarde multiplica os exemplos, as demonstrações e as comparações para mostrar que quando o desenvolvimento não obedece exclusivamente à biologia e à física, mas implementa dimensões sociais, é sempre algum tipo de "processus" de imitação que está tomando forma. Essa teoria, o autor a nutre com múltiplas comparações extraídas do estudo de línguas, religiões, regimes políticos, legislações, moral, artes, costumes e necessidades econômicas. É, ele argumenta no capítulo sobre o direito, a imitação que garantiu a adesão massiva ao sistema de mapas ("chartes”) municipais; a propagação, na França, dos costumes de Lorris juntamente com aquele das cidades do Reno, dos costumes de Colônia ou dos costumes de Magdeburg em Halte, Leipzig, Breslau, depois de Breslau na Sibéria, na Boêmia, na Polônia, na Morávia ${ }^{71}$. Da mesma forma, a comparação serve para mostrar que a tortura, o júri ou a codificação se impuseram na Europa por imitação.

Paralelamente, Josef Kolher empreende, em 1885 - professor de direito em Würzburg, ele será professor em Berlim em 1888 - a mostrar que todas as sociedades passam, ainda que a ritmos diferentes, por uma mesma série de etapas jurídicas de desenvolvimento segundo um "processus" evolucionista ${ }^{72}$. A comparação entre o desenvolvimento dos direitos islâmicos, chineses, berberes e do Ceilão lhe dá elementos de prova de que povos, que não tiveram

\footnotetext{
${ }^{69}$ AUDREN, F.; SALMON, L. Tarde. ARABEYRE, Patrick; HALPÉRIN, Jean-Louis; KRYNEN, Jacques (Orgs.). Dictionnaire historique des juristes français (XIIe - XXe siècle). Paris: Presses Universitaires de France, 2007, p. 730.

70 TARDE, Gabriel de. Les lois de l'imitation (1890). 2. ed. Paris: Alcan, 1895, p. 57.

${ }^{71}$ Ibidem, p. 339-340.

72 KOHLER, Josef. Rechtsvergleichende Studien über islamitisches Recht, das Recht der Berbern, das chinesische Recht und das Recht auf Ceylon. Berlim: Heymann, 1889.
} 
relações mútuas, atravessaram espontaneamente estágios sucessivos similares. A comparação jurídica permite, assim, alimentar a ideia de que o motor do desenvolvimento paralelo não é a imitação, mas o evolucionismo. Em 1900, no Congresso internacional de direito comparado de Paris, Tarde e Kolher confrontam suas respectivas teorias por meio de comunicações interpostas. Lambert, que foi encarregado de relatar os trabalhos enviados aos organizadores do congresso, resume as duas concepções: para La Grasserie e Kolher, existiria uma lei que leva todos os povos a seguirem um encadeamento regulamentado, uniforme e inevitável que sempre os conduz, ao final do "processus", aos mesmos resultados jurídicos; inversamente, para Tarde, ainda explica Lambert, existem diversas trajetórias jurídicas que levam a poder classificar os tipos jurídicos como se classificam as espécies animais ou vegetais e continuemos fiéis a Tarde - que se unem por imitação de uma civilização por uma outra ${ }^{73}$.

\section{COMPARAR PARA UNIFICAR O DIREITO}

O autor do século XIX pode ter como motivação ("mobile”) principal unificar o direito em vigor, um motivo que se afirma à medida que avançamos no século. Antes dos anos 17801800, a diversidade jurídica se acomodava, na Europa e nos territórios da América do Norte e da América Latina, a uma relativa unidade do direito, garantida pelo ius commune e o direito natural dos modernos. No século XIX, cada Estado - tanto os Estados novos quanto os Estados antigos - constrói sua própria legislação, certamente com a ajuda de modelos jurídicos que circulam no mundo, mas com uma abordagem assumida de nacionalismo jurídico $^{74}$. Ora, em reação a essa lógica, numerosos juristas propõem outro caminho: o de um novo direito comum que seria fruto da comparação de direitos, cuja forma e fundo variam, além disto, segundo os homens, os períodos e domínios do direito.

É, evidentemente, um dos grandes projetos de certa doutrina comercialista: em nome da vocação dos negócios e para além do apagamento progressivo do antigo jus mercatorum

\footnotetext{
${ }^{73}$ LAMBERT, É. Synthèse des travaux envoyés au congrès. In: Congrès international de droit comparé (1900). Paris: Sirey, 1905, p. 30.

${ }^{74}$ Sobre essa oscilação, PADOA-SCHIOPPA, Antonio. Storia del diritto in Europa: dal medioevo all'età contemporanea. Bologna: Il Mulino, 2007; CAENEGEM, R. C. van. European law in the past and the future: unity and diversity over two millennia. Cambridge, U.K.: Cambridge University Press, 2002; HATTENHAUER, Hans. Europäische Rechtsgeschichte. 4., durchges. und erw. Aufl. Heidelberg: Müller, 2004. (Ius Communitatis); SCHULZE, Reiner (Org.). Französisches Zivilrecht in Europa während des 19. Jahrhunderts. Berlin: Duncker \& Humblot, 1994. (Schriften zur europäischen Rechts- und Verfassungsgeschichte, Bd. 12); HALPERIN, Jean-Louis. L'approche historique et la problématique du jus commune. Revue internationale de droit comparé, v. 52, n. 4, p. 717-731, 2000.
} 
em favor das codificações nacionais, numerosos autores iniciam um trabalho de comparação com vistas a um direito comercial unificado. Assim, o italiano Giuseppe Montanelli professor em Pisa a partir de 1840, ele milita pela independência da Itália segundo uma postura federalista antiunitária - em sua Introduzione filosofica allo studio del diritto commerciale positivo (1847). Ele clama que "os ânimos ("esprits") que se elevaram aos aspectos mais gerais das ciências sociais, descem dessas alturas até o exame das legislações comerciais positivas que governam as nações civis e, comparando-as umas às outras, que se propõem o modelo legislativo que poderia ser adotado como um Código de direito comercial comum"75.

É, igualmente, um dos objetivos, no direito civil, de alguns autores proeminentes dentro da Société de législation comparée ${ }^{76}$. Assim, o francês René Saleilles, quando reúne o primeiro Congresso internacional de direito comparado de Paris em 190077. Ele propõe operar uma inversão de objetivos no que diz respeito à comparação. "Por muito tempo [explica ele] foi concebido apenas como uma espécie de constatação das diversidades legislativas entre países de uma civilização semelhante"78. Doravante, convém fazer "a aproximação racional das diversas legislações, tomadas nas suas fórmulas jurídicas e nos seus resultados práticos, a fim de pesquisar e estudar se, dessa interpretação pensada, se extrai um tipo predominante que possa servir de modelo, ao menos de modo aproximativo"79; que poderia se concretizar "quer por via legislativa, quer por via consuetudinária e doutrinal [...], quer por acordo internacional" $"$.

\footnotetext{
${ }^{75}$ MONTANELLI, Giuseppe. Introduzione filosofica allo studio del diritto commerciale positivo. Pisa: Sampteria Pierraccini, 1847.

${ }^{76}$ FALELAVAKI, Y. Le réseau constitué autour de la Société de législation comparée (1869-1900). In: LE YONCOURT, Thiphaine (Org.). L'Idée de fonds juridique commun dans l'Europe du XIXe siècle: les modèles, les réformateurs, les réseaux. Rennes: Presses universitaires de Rennes, 2014. (Collection 'L'univers des normes"), p. 277 e s.

77 Sobre os motivos ('mobiles') dos organizadores do congresso, FALÉLAVAKI, Yannick. L'histoire d'une conversion: la doctrine française du XIXe siècle et le recours à la comparaison juridique. Tese, Rennes 1, Rennes, 2016.

${ }^{78}$ SALEILLES, R. Rapport présenté à la commission d'organisation sur l'utilité, le but et le programme du congrès, 1900. In: Congrès international de droit comparé (1900). Paris: Sirey, 1905, p. 9-10. Sobre Saleilles, ROBERT, Jacques-Henri. Saleilles et le comparatisme. Revue d'histoire des facultés de droit et de la culture juridique, du monde des juristes et du livre juridique, p. 143-149, 1991; GROSSI, Paolo. Assolutismo giuridico e diritto privato. Milano: Giuffrè, 1998. (Per la storia del pensiero giuridico moderno, 52), p. 191 et seq.; JAMIN, Christophe. Le vieux rêve de Saleilles et Lambert revisité. A propos du centenaire du Congrès international de droit comparé de Paris. Revue internationale de droit comparé, v. 52, n. 4, p. 733-751, 2000; ARAGONESES, Alfons. Un jurista del modernismo: Raymond Saleilles y los orígenes del derecho comparado. Madrid: Dykinson, 2009.

${ }^{79}$ Ibidem, p. 11.

${ }^{80}$ Ibid., p. 14.
} 
É, novamente, o programa desenvolvido, em matéria penal, pelo alemão von Liszt professor de direito penal por sua vez em Giessen (1879-1882), Marbourg (1882-1889), Halle (1889-1899) e Berlim (1899-1919); ele inicia um movimento em favor da reforma penal na Alemanha que se materializa através da fundação de uma revista, de um instituto e de uma rede de acadêmicos e práticos - quando introduz La législation pénale comparée publiée par l'Union internationale de droit pénal (1894). Em seu Coup d'œil rétrospectif et plans d'avenir, ele opera uma releitura crítica das tendências comparativas anteriores antes de definir um novo rumo ${ }^{81}$. É no Congresso de Berna (1890), lembra ele, que a União Internacional de Direito Penal tomou a resolução de publicar uma exposição comparativa do direito penal na Europa. Ora, a preparação do código penal da confederação helvética oferecia aos congressistas um quadro de reflexão propício e fecundo. De fato, o Conselho federal suíço havia, com efeito, confiado a Stoos o cuidado de reunir e conferir todas as legislações penais cantonais (um primeiro trabalho publicado em 1890), depois extrair os princípios gerais comuns (dois volumes publicados em 1892 e 1893). Estava traçado um rumo, sobretudo porque Stoos fazia parte da equipa formada por Liszt: tratava-se, explica este, de aplicar o modelo suíço à Europa, ou seja, reunir e conferir as legislações penais francesa, alemã, italiana, belga, espanhola etc. e delas tirar os princípios gerais comuns, com vista a promulgar um dia um código penal europeu ${ }^{82}$. "Mesmo assim [explica Liszt], nosso objetivo distante não era o desenvolvimento de um Código Penal Europeu [espero poder demonstrar que essa ideia não é uma utopia, como poderia parecer à primeira vista], um estudo comparativo do direito penal da Europa, considerado em si mesmo, teria um valor inestimável para qualquer pessoa na esfera de ação do direito penal". É por isto que Liszt faz questão de condenar as abordagens comparativas que se desviam para tomar outro do rumo ${ }^{83}$ :

\footnotetext{
${ }^{81}$ VON LISZT, Franz. La législation pénale comparée publiée par l'Union internationale de droit pénal. Berlim, Paris, Roma, Lisboa: [s. n.], 1894, vol. 1, p. xi. e sobre Liszt, SCHMIDT, Eberhard. Einführung in die Geschichte der deutschen Strafrechtspflege. Göttingen: Vandenhoeck, 1964, p. 357 e s.

${ }^{82}$ Sobre o programa da União, BELLMANN, Elisabeth. Die Internationale Kriminalistische Vereinigung, 18891933. Frankfurt am Main; New York: P. Lang, 1994. (Rechtshistorische Reihe, Bd. 116); WETZELL, Richard F. Inventing the criminal: a history of German criminology, 1880 - 1945. Chapel Hill, [NC]: Univ. of North Carolina Press, 2000. (Studies in legal history), p. 33 e s. Sobre as ligações entre Liszt, Stoos e a codificação penal suiça: GRAVEN, J. Frantz von Liszt et le Nouveau droit penal suisse. Revue Internationale de Droit Pénal, 1951, p. 209 et seq. Esses trabalhos preparatórios culminam no texto de Carl Stoos (STOOS, Carl. Exposé des motifs de l'avant-projet de code pénal suisse. Tradução por Alfred Gautier. Genebra: [s. n.], 1893) um projeto que foi aceito por referendo em 1938 e entrou em vigor em 1942.

${ }^{83}$ VON LISZT, Franz. La législation pénale comparée publiée par l’Union internationale de droit pénal.

Berlim, Paris, Roma, Lisboa: [s. n.], 1894, p. xix.
} 
O que muitas vezes é considerado como tal não é legislação comparada, a saber: o tratado sobre um direito nacional isolado, por mais remoto que seja. Quem lida com o direito penal chinês não faz para tanto uma legislação comparada, tampouco aquele que escreve um manual de direito penal alemão ou aquele que comenta o Código penal francês. Mas, novamente, a justaposição de dois ou mais direitos não é em si legislação comparada; e, por mais paradoxal que essa frase possa parecer, mesmo a comparação desses direitos, a operação de trazer à tona o que eles têm em comum e como eles diferem, não pode ser considerada como tal.

A verdadeira legislação comparada é julgada pela motivação (“mobile”) que anima o autor: "é necessário que se busque e se encontre algo novo e independente, que difere direitos isolados e comparados e não esteja, desde o início, fechado em si mesmo". "Para além do direito hoje em vigor, nosso olhar busca o novo direito do futuro. Antes de nos entregar à busca por esse direito, devemos ter a medida dele, conhecer seu objeto e finalidade" ${ }^{84}$. E esse objetivo, explica Liszt, é a formação de um código penal europeu. Ele descarta com vigor aqueles que rejeitam este projeto ou pensam que é utópico ${ }^{85}$ :

Em minha convicção, hoje é possível a qualquer momento redigir um Código Penal que, nos seus princípios, seria aceitável para a França, bem como para a Alemanha, a Áustria-Hungria ou os Países Baixos. Qualquer pessoa que argumente o contrário ignora a história do direito criminal. A legislação penal napoleônica não está, quanto a todos os seus princípios fundamentais, em vigor no Estado principal da Alemanha há mais de meio século e em todo o Império alemão a mais de vinte anos? Se contestaria que o Código da Baviera foi recebido nos estados da América do Sul e na Grécia? Repito: só os princípios estão em jogo.

Liszt tira duas consequências disto. A rigor, comparação jurídica é a atitude que consiste em afirmar, no final do exame comparativo das legislações em vigor: "é assim e não de outra forma que se deve fazer a vossa lei”. E, a rigor, a comparação jurídica é a atitude que busca desenvolver a ciência do direito, forçando a teoria nacional a se elevar acima de si mesma graça aos trabalhos estrangeiros, ao explicar as noções de imputabilidade, de intenção, de negligência, de tentativa, de cumplicidade etc., independentemente das leis nacionais ${ }^{86}$. As leis dirão quando e como a tentativa é criminalmente punida, mas é a ciência que, na dimensão internacional, explicará a própria noção de tentativa. Para Liszt, o motivo (“mobile”) da comparação é, portanto, unificar o direito, não apenas pela formação de um direito penal comum, mas também pela formação de uma ciência do direito criminal comum;

\footnotetext{
${ }^{84}$ VON LISZT, Franz. La législation pénale comparée publiée par l’Union internationale de droit pénal. Berlim, Paris, Roma, Lisboa: [s. n.], 1894, p. xxi.

${ }^{85}$ Ibid., p. xx.

${ }^{86}$ Ibid., p. xxii.
} 
aquela que tem o papel de "reunir, com os Códigos penais, a ciência e a jurisprudência dos diversos países, para formar uma unidade superior"\$7.

Para o comercialista Montanelli, o civilista Saleilles e o penalista Liszt, o motivo ("mobile") justifica métodos bastante vizinhos: trata-se, para o cientista, de reunir as diversas legislações, de examiná-las, compará-las, depois apresentar uma dentre elas como modelo ou extrair princípios gerais comuns a fim de, em segundo momento, apresentá-los como lei comum. Montanelli reclama "o modelo legislativo que poderá ser adoptado como Código de direito comercial comum"; Saleilles busca "um tipo predominante que possa servir de modelo, pelo menos de modo aproximativo"; Liszt considera o momento-chave em que o comparatista será capaz de afirmar em face dos Estados da Europa: "é assim e não de outra forma que se deve fazer a vossa lei”.

\section{CONCLUSÃO}

Diversidade de motivações ("mobile"), diversidade de métodos, diversidade de tom... A comparação, no século XIX, oferece uma grande riqueza de abordagens; uma riqueza tal que alguns autores pioneiros já a abordam como objeto de estudo. Eles examinam, de fora, as comparações operadas por outros, de dentro. Tomemos o caso de Emerico Amari que, em 1857, publica no exílio - teve que deixar a ilha após a revolução abortada de 1848 e a restauração dos Bourbons - sua Critica di una scienza delle legislazioni comparate $^{88}$. Esta obra estuda, sob o ângulo da comparação jurídica, as obras maiores desde Aristóteles e Cícero a Bodin, Grotius, Montesquieu ou Bentham ${ }^{89}$. Amari se inspira nas teses de Vico sobre o desenvolvimento histórico das sociedades e procura aplicar a teoria do progresso à comparação para construir a unidade do gênero humano. Como tal, ele se junta aos autores que comparam para alimentar uma teoria histórica. No entanto, a intenção é também analisar e classificar as abordagens comparativas ${ }^{90}$ :

\footnotetext{
${ }^{87}$ VON LISZT, Franz. La législation pénale comparée publiée par l’Union internationale de droit pénal. Berlim, Paris, Roma, Lisboa: [s. n.], 1894, p. xxiv.

${ }^{88}$ AQUARONE, Alberto. Amari Emerico. In: ISTITUTO DELLA ENCICLOPEDIA ITALIANA (Org.). Dizionario biografico degli Italiani. Roma: Istituto della Enciclopedia italiana, 1960. 2v., t. 1, p. 634 e s.

${ }^{89}$ BENTIVEGNA, Giuseppe. Filosofia civile e diritto comparato in Emerico Amari. Napoli: Guida, 2003. (Strumenti e ricerche, 18), p. 106 e s.

${ }^{90}$ AMARI, Emerico. Critica e storia di una scienza delle legislazioni comparate. Saggi di filosofia civile. v. 4. Gênes: R. I. de' Sordo-Muti, 1857. p. 04-05.
} 
A variedade de propósitos perseguidos por esta doutrina e a importância dos resultados aos quais ela aspira têm suscitado a atenção e o trabalho de uma multidão de autores talentosos. A utilidade prática que daí resulta, em uma era tão poderosamente utilitarista, ganhou o favor daqueles que, habilmente, não são muito benevolentes com as ciências, a saber, os príncipes. $\mathrm{Na}$ verdade, de todas as disciplinas jurídicas, essa legislação comparada é a que tem sido mais bajulada ou menos contestada.

Daí a retrospectiva. Amari, após ter explicado o que é uma ciência e o que pode ser a ciência da legislação comparada (p. 11 et seq.), oferece uma tipologia que denomina seu ofício ou seus fins. Ele distingue o ofício prático do ofício científico (p. 47 et seq.), em seguida, enumera os fins práticos: conhecer as leis comerciais estrangeiras; estudar a circulação das legislações, seja por instinto de imitação, seja pela vontade de propagação; pesquisar a origem das leis; fomentar a corrida pela primazia entre as nações (p. 48 et seq.). Em seu ofício científico, continua ele, as legislações comparadas examinam os direitos como manifestação da lei natural (p. 87 et seq.), como a implementação do direito abstrato nas leis, em particular por sua enumeração e classificação (p. 121 et seq.), como método de descoberta da história ou da biologia das leis, notadamente na sua relação com o clima, a religião, os costumes etc. (p. 158 et seq.), como um método para descobrir a perenidade das leis (p. 206 et seq.), para relacionar direito e natureza comum das nações (p. 258 et seq.), para alimentar a teoria do progresso que se nutre das transferências de legislação de um povo a outro (p. 319 et seq.).

A abordagem inovadora de Amari (1857) já permite abarcar as obras dos seus predecessores e de seus contemporâneos. Porém, é após a formalização do direito comparado como disciplina jurídica particular que os inventários e clarificações se multiplicarão ${ }^{91}$. Portanto, nos esforçaremos para classificar as diferentes abordagens comparativas e separar, entre elas, o que realmente se enquadraria no direito comparado e o que não se enquadraria. Em 1928, por exemplo, o norte-americano John Henry Wigmore - especialista e reformador do direito japonês que se torna professor da Northwestern Law School da Universidade de Chicago e diretor do departamento de direito comparado da American Bar Association (1907) - diferencia a comparative nomoscopy, que descreve outros sistemas jurídicos como fatos, a

\footnotetext{
${ }^{91}$ Sobre essa virada ocidental, J HUSA, Jaakko. A new introduction to comparative law. Oxford: Bloomsbbury, 2015, p. 6 et seq. ; LEGEAIS, Raymond. Pour une introduction au droit comparé : développement du droit comparé et diversification de ses fonctions. In: LEGEAIS, Raymond (Org.). Grands systèmes de droit contemporains: Approche comparative. Paris: LexisNexis, Litec, 2008, p. 433 e s. ; GLENN, H. Patrick. Vers un droit comparé intégré? Revue internationale de droit comparé, v. 51, n. 4, p. 841-852, 1999; ZWEIGERT, Konrad; KÖTZ, Hein. Einführung in die Rechtsvergleichung. Tübingen: Mohr, 1996. p. 47 et seq.; ANCEL, Marc. Les grandes étapes de la recherche comparative au XXe siècle. In: Studi in Memoria di Andrea Torrente. 2 v. t. 1. Milão: Giuffrè, 1968. p. 20 et seq.
} 
comparative nomothetics, que questiona as respectivas qualidades dos diversos sistemas jurídicos, e a comparative nomogenetics, que se interessa sobre a evolução dos sistemas uns em relação a outros ${ }^{92}$. Em 1931, o francês Édouard Lambert - professor de história do direito, direito civil comparado e direito internacional privado na Universidade de Lyon, onde funda o primeiro instituto francês de direito comparado (1921) - dissocia o direito comparativo descritivo, que enumera e analisa os sistemas jurídicos atuais e passados, bem como a diversidade de seus princípios e mecanismos, da história comparada do direito, que, através de uma história universal do direito, busca as leis que conduzem a evolução das instituições jurídicas, e da legislação comparada, que descreve o tronco comum no qual se enxerta a pouco e pouco as legislações nacionais ${ }^{93}$. Em 1932, o suíço Walther Hug - professor associado da Universidade de Harvard (1930), depois professor de direito privado na Universidade suíça de Saint Gall (1932), que cria sua própria Fondation pour le développement de la recherche scientifique en droit - afasta do seu propósito o estudo dos direitos estrangeiros, que é "um simples pré-requisito para o direito comparado" e distingue o direito comparado no sentido estrito do termo (que inclui dois níveis: a comparação entre os sistemas estrangeiros e o sistema interno, a análise objetiva e sistemática dos sistemas jurídicos desenvolvidos) da história comparada do direito que, por um lado, compara a história de dois ou mais sistemas jurídicos e que, por outro lado, se interessa pela história universal do direito para retraçar a evolução de tal ou qual instituição jurídica em particular e a evolução jurídica global de acordo com os sistemas e os períodos ${ }^{94}$. Wigmore, Lambert, Hug... Poderíamos continuar a retrospectiva até os dias de hoje.

\section{REFERÊNCIAS}

AMARI, Emerico. Critica e storia di una scienza delle legislazioni comparate: Saggi di filosofia civile. Gênes: R. I. de' Sordo-Muti, 1857.

ANCEL, Bertrand. Le droit international privé comparé. Paris: Éd. Panthéon-Assas, 2007.

ANCEL, Marc. Les grandes étapes de la recherche comparative au XXe siècle. In: Studi in Memoria di Andrea Torrente. Milão: Giuffrè, 1968, v. 1. 2v.

\footnotetext{
${ }^{92}$ WIGMORE, John Henry. A panorama of the World's Legal Systems. 3 v. Saint Paul: West Publishing Company, 1928, p. 1120.

${ }^{93}$ LAMBERT, E. Comparative Law. In: SELIGMAN, E. (Org.). Encyclopaedia of the Social Sciences. New York: Macmillan, 1931, v. 4., p. 126.

${ }^{94}$ HUG, Walther. The History of Comparative Law. Harvard Law Review, v. 45, n. 6, p. 1027-1070, 1932.
} 
AQUARONE, Alberto. Amari Emerico. In: ISTITUTO DELLA ENCICLOPEDIA ITALIANA (Org.). Dizionario biografico degli Italiani. Roma: Istituto della Enciclopedia italiana, 1960. 2v.

ARABEYRE, Patrick; HALPÉRIN, Jean-Louis; KRYNEN, Jacques (Orgs.). Dictionnaire historique des juristes français (XIIe - XXe siècle). Paris: Presses Universitaires de France, 2007.

ARAGONESES, Alfons. Un jurista del modernismo: Raymond Saleilles y los orígenes del derecho comparado. Madrid: Dykinson, 2009.

ARANEDA, C. El derecho canónico en el Código Civil de la República de Chile. In: MARTINIC, M.; TAPIA, M. (Orgs.). Sesquicentenario Del Codigo Civil de Andres Bello: Pasado, Presente Y Futuro de La Codificacion. Paris: LexisNexis, 2005, p. 203 et ss.

AUDREN, F.; SALMON, L. Tarde. ARABEYRE, Patrick; HALPÉRIN, Jean-Louis; KRYNEN, Jacques (Orgs.). Dictionnaire historique des juristes français (XIIe - XXe siècle). Paris: Presses Universitaires de France, 2007, p. 730.

BATBIE, Anselme. Traité théorique et pratique de droit public et administratif. Paris: Cotillon, 1862.

BAUMAN, R. Comparative law in ancient times. In: TAY, A (Org.). Law and Australian Thinking in the 1980s. Sidney: Organizing Committee of the 12th International Congress of Comparative Law, 1986, p. 99 e ss.

BELLMANN, Elisabeth. Die Internationale Kriminalistische Vereinigung, 1889-1933. Frankfurt am Main; New York: P. Lang, 1994. (Rechtshistorische Reihe, Bd. 116).

BENTHAM, Jeremy. Constitutional Code (1830), the works of Jeremy Bentham published under the superintendence of his executor, John Bowring. Edimburgo: [s. n.], 1843. 9v.

BENTIVEGNA, Giuseppe. Filosofia civile e diritto comparato in Emerico Amari. Napoli: Guida, 2003. (Strumenti e ricerche, 18).

BIROCCHI, Italo; CORTESE, Ennio; MATTONE, Antonello; et al (Orgs.). Dizionario biografico dei Giuristi italiani (XII-XX secolo). Bologna: Società Editrice il Mulino, 2013. 2v.

BLAXLAND, George. Codex Legum Anglicanarum: Or, A Digest of Principles of English Law; Arranged in the Order of the Code Napoleon. Londres: Henry Butterworth, 1839.

BOERESCU, Vasile. La Roumanie après le Traité de Paris du 30 mars 1856. Paris: [s. n.], 1859 .

BOISSONADE, G. Législation comparée des droits du conjoint survivant. Revue de législation ancienne \& moderne française et étrangère, v. 3, p. 643 e ss., 1873. 
BOISSONADE, Gustave. Le nouveau code civil italien comparé au Code Napoléon. Revue Pratique de droit français, v. XXVI, 1868.

BOYER, Pierre-Louis. Un cercle intellectuel au coeur de l'évolution de la doctrine juridique: l'Académie de législation de Toulouse (1851-1958). Paris: LGDJ, 2014. (Bibliothèque d'histoire du droit et droit romain, tome 27).

BRAUNEDER, Willhelm. Juristen in Österreich: 1200-1980. Viena: Verlag Orac, 1986.

BRAVO-LIRA, B. Derecho romano y codificación civil. De los dos grandes modelos euorpeos, austriaco (1797) y Francés (1804), al Código de Chile (1855). In: MARTINIC, M.; TAPIA, M. (Orgs.). Sesquicentenario del Codigo Civil de Andres Bello: Pasado, Presente Y Futuro de La Codificacion. Paris: LexisNexis, 2005. p. 171 s.

BURGE, William. Commentaries on Colonial and Foreign Laws generally, and in their conflict with each other, and with the law of England. Londres: Saunders and Benning, 1838. $4 \mathrm{v}$.

CAENEGEM, R. C. van. European law in the past and the future: unity and diversity over two millennia. Cambridge, U.K.: Cambridge University Press, 2002.

CANTO, Patrick. La revue de législation et de jurisprudence: 1835-1853. Tese (Direito) Université de Lyon Jean Moulin, 1999.

CARCANO, G. Cassazione o terza instanza? Monitore dei tribunali, p. 974 et seq., 1871. p. 1061 et seq.

CHAMOCHO, Miguel Angel. Le contentieux administratif en Espagne au XIXe siècle: entre particularismes et importation du modèle français. In: HAUTEBERT, J.; SOLEIL, S. (Orgs.). Modèles français, enjeux pollitiques et élaboration des grands textes de procédure en Europe. 2v. v. 1. Paris: Éditions juridiques techniques, 2007, p. 219 et seq.

CHAMOCHO, Miguel Angel. Les réformes administratives provinciales en Espagne et le modèle français au milieu du XIXè siècle. Revue historique de droit français et étranger, n. 3, p. 415-435, 2007.

CIANCIO, C. Les congrès internationaux de droit commercial : un réseau de commercialistes européens à la recherche d'un droit uniforme. In: LE YONCOURT, Thiphaine (Org.). L'Idée de fonds juridique commun dans l'Europe du XIXe siècle: les modèles, les réformateurs, les réseaux. Rennes: Presses universitaires de Rennes, 2014. (Collection 'L'univers des normes"), p. $253 \mathrm{~s}$.

DARWIN, Charles. La descendance de l'homme et la sélection naturelle (1871). Trad. E. Barbier. Paris: [s. n.], 1891.

DE SMET, Pierre Jean. Voyages aux montagnes rocheuses et séjour chez les tribus indiennes de l'Orégon (États-Unis). 2. ed. Paris: Decaux et Cie., 1873. 
DEN OTTER, Sandra. 'A legislating empire': Victorian political theorists, codes of law, and empire. In: BELL, Duncan (Org.). Victorian Visions of Global Order: Empire and International Relations in Nineteenth-Century Political Thought. Cambridge: Cambridge University Press, 2007, p. 89-112. (Ideas in Context).

DEROUSSIN, David (Org.). Le renouvellement des sciences sociales et juridiques sous la IIIe République: la Faculté de droit de Lyon. Paris: Éd. La Mémoire du Droit, 2007. (Collection Recueil d'études, 2).

DESMET, Piet. La linguistique naturaliste en France (1867-1922): nature, origine et évolution du langage. Leuven: Peeters, 1996.

DONAHUE, Charles. Comparative Law before the Code Napoléon. In: REIMANN, Mathias; ZIMMERMANN, Reinhard (Orgs.). The Oxford Handbook of Comparative Law. [s.1.]: Oxford University Press, 2006, p. 2-32.

DORSETT, Shaunnagh; MCLAREN, John D (Orgs.). Legal histories of the British Empire: laws, engagements, and legacies. New-York: Routledge, 2014.

DUBOUCHET, Paul. La pensée juridique avant et après le Code civil. Lyon: L' Hermès, 1992.

DUBOUCHET, Paul. Philosophie et doctrine du droit chez Kant, Fichte, et Hegel. Paris: L'Harmattan, 2005. (Ouverture philosophique).

DURAND, Bernard. Introduction historique au droit colonial. Paris: Economica, 2015. (Corpus. Histoire du droit).

ELLIOTT, E. Donald. The Evolutionary Tradition in Jurisprudence. Faculty Scholarship Series, 1985.

FALELAVAKI, Y. Le réseau constitué autour de la Société de législation comparée (18691900). In: LE YONCOURT, Thiphaine (Org.). L'Idée de fonds juridique commun dans l'Europe du XIXe siècle: les modèles, les réformateurs, les réseaux. Rennes: Presses universitaires de Rennes, 2014. (Collection “L'univers des normes"), p. 277 e s.

FALÉLAVAKI, Yannick. L'histoire d'une conversion : la doctrine française du XIXe siècle et le recours à la comparaison juridique. Tese, Rennes 1, Rennes, 2016.

FEOLA, Raffaele. Istituzioni e cultura giuridica. Nápoles: Ed. Scientifiche Italiani, 1993. 3v.

FOELIX, Jean-Jacques-Gaspard. Traité de droit international privé : Des conflits de lois de différentes nations en matière de droit privé. Paris: Joubert, 1843.

FOSTER, Hamar; BUCK, A. R; BERGER, Benjamin L (Orgs.). The grand experiment: law and legal culture in British settler societies. Vancouver: UBC Press, 2008.

GALLOSTRA Y FRAU, Colección bibliográphica de lo contencioso-administrativo. Madrid: Imprenta y Fundición de Manuel Tello, 1881.p. 117. 
GAUDEMET, Jean. Les Écoles historiques du droit en France et en Allemagne. Revue d'histoire des facultés de droit et de la science juridique, v. 19, p. 87-124, 1998.

GLENN, H. Patrick. Vers un droit comparé intégré? Revue internationale de droit comparé, v. 51, n. 4, p. 841-852, 1999.

GÓMEZ DE LA SERNA, P. Instituciones del derecho administrativo español. Madrid: D. Vincente de Lalama, 1843. 2v.

GORLA, Gino. Prolegomeni ad una storia del diritto comparato europeo. Il Foro Italiano, v. 103, 1980.

GRAVEN, J. Frantz von Liszt et le Nouveau droit penal suisse. Revue Internationale de Droit Pénal, 1951, p. 209 e ss.

GROSSI, Paolo. Assolutismo giuridico e diritto privato. Milano: Giuffrè, 1998. (Per la storia del pensiero giuridico moderno, 52).

GROSSI, Paolo. Scienza giuridica italiana: un profilo storico, 1860-1950. Milão: Giuffrè, 2000.

GUASTALLA, M. Ordinamento giudiziario: supremo stadio di giurisdizione. La legge, n. I, p. 61 et seq., 1861.

GUTAN, M. La réception de l'institution napoléonienne du préfet en Roumanie. In:

MOQUET-ANGER, Marie-Laure (Org.). Les institutions napoléoniennes. Paris:

L'Harmattan, 2006.

GUYON, Gwenaël. Les partisans de la codification en Angleterre (XIXe siècle) : la question du droit pénal entre utilitarisme, modernisation du common law et modèle juridique français. Tese, Rennes 1, Rennes, 2012.

GUZMÁN BRITO, A. La Formación del sistema general del Código Civil de Chile y los sistemas de los códigos existentes hacia 1852. In: MARTINIC, M.; TAPIA, M. (Orgs.). Sesquicentenario Del Codigo Civil de Andres Bello: Pasado, Presente Y Futuro de La Codificacion. Paris: LexisNexis, 2005, p. 123 e ss.

HAKIM, Nader. L'autorité de la doctrine civiliste française au XIXe siécle. Paris: L.G.D.J, 2002. (Bibliothèque de droit privé, t. 381).

HAKIM, Nader; MELLERAY, Fabrice (Orgs.). Le renouveau de la doctrine française: les grands auteurs de la pensée juridique au tournant du XXe siècle. Paris: Dalloz, 2009.

(Méthodes du droit).

HALPÉRIN, Jean-Louis. Entre nationalisme juridique et communauté de droit. 1re éd. Paris: Presses universitaires de France, 1999. (Les voies du droit). 
HALPÉRIN, Jean-Louis. Histoire de l'état des juristes - Allemagne, XIXe-XXe siècles. Paris: Garnier, 2015.

HALPERIN, Jean-Louis. L'approche historique et la problématique du jus commune. Revue internationale de droit comparé, v. 52, n. 4, p. 717-731, 2000.

HALPÉRIN, Jean-Louis. Laboulaye, historien du droit et/ou comparatiste. Revue internationale de droit comparé, v. 63, n. 3, p. 517-525, 2011.

HATTENHAUER, Hans. Europäische Rechtsgeschichte. 4., durchges. und erw. Aufl. Heidelberg: Müller, 2004. (Ius Communitatis).

HEGEL, Georg Wilhelm Friedrich. Principes de la philosophie du droit. Trad. A. Kaan. Paris: Gallimard, 1940.

HENDERSON, Jennifer Denise. Blaze of Reputation and the Echo of a Name: The Legal Career of Peter Stephen du Ponceau in Post-Revolutionary Philadelphia. Tese, The Florida State University, Tallahassee, Florida, 2004.

HERRERA, Carlos-Miguel. Les juristes face au politique le droit, la gauche, la doctrine sous la Troisième République. Paris: Éd. Kimé, 2005. 2v.

HOOPER, Glenn; YOUNGS, Tim (Orgs.). Perspectives on travel writing. Aldershot, Burlington: Ashgate, 2004. (Studies in European cultural transition, v. 19).

HUG, Walther. The History of Comparative Law. Harvard Law Review, v. 45, n. 6, p. 10271070, 1932.

HUMPHREYS, James. Observations on the actual situation of english law of real property, with the outlines of a Code. Londres: [s. n.], 1826.

HUSA, Jaakko. A new introduction to comparative law. Oxford: Bloomsbbury, 2015.

JAMIN, Christophe. Boissonade Et Son Temps. Archives de Philosophie du Droit, v. 44, p. 285-312, 2000.

JAMIN, Christophe. Boissonade et son temps. Archives de philosophie de droit, n. 44, p. 285 et seq., 2000.

JAMIN, Christophe. Le vieux rêve de Saleilles et Lambert revisité. A propos du centenaire du Congrès international de droit comparé de Paris. Revue internationale de droit comparé, v. 52, n. 4, p. 733-751, 2000.

JAYME, Erik. Identité culturelle et intégration: le droit international privé postmoderne : Recueil de cours de l'Académie de droit international. La Haye: Martinus Nijhoff Publishers, 1995.

JESTAZ, Philippe; JAMIN, Christophe. La doctrine. Paris: Dalloz, 2004. (Méthodes du droit). 
JOUANJAN, Olivier. Une histoire de la pensée juridique en Allemagne (1800 - 1918): idéalisme et conceptualisme chez les juristes allemands du XIXe siècle. 1. ed. Paris: Presses Univ. de France, 2005.

KEISTINE, Jacques-Olivier. La revue Foelix (de 1834 à 1843) : Un miroir allemand pour la science du Droit en France. These de doctorat, Université Paris-Est Marne-la-Vallée, Marnela-Vallée, 2011.

KERVÉGAN, Jean-François; MARMASSE, Gilles (Orgs.). Hegel penseur du droit. Paris: CNRS Éditions, 2003.

KIRKBY, Diane Elizabeth; COLEBORNE, Catharine (Orgs.). Law, history, colonialism: the reach of empire. Manchester: Manchester University Press, 2001. (Studies in imperialism).

KOBAYASHI, Masako. French Legal Advisor in Meiji Japan (1873-1895): Gustave Émile Boissonade de Fontarabie. Tese, University of Hawaii, 1996.

KOHLER, Josef. Rechtsvergleichende Studien über islamitisches Recht, das Recht der Berbern, das chinesische Recht und das Recht auf Ceylon. Berlim: Heymann, 1889.

LAMBERT, E. Comparative Law. In: SELIGMAN, E. (Org.). Encyclopaedia of the Social Sciences. New York: Macmillan, 1931, v. 4.

LAMBERT, É. Synthèse des travaux envoyés au congrès. In: Congrès international de droit comparé (1900). Paris: Sirey, 1905, p. 30.

Law Magazine, fevereiro 1838 - maio 1838, p. 107.

Legal Observer, novembro 1837 - abril 1838, p. 370.

LEGEAIS, Raymond. Pour une introduction au droit comparé : développement du droit comparé et diversification de ses fonctions. In: LEGEAIS, Raymond (Org.). Grands systèmes de droit contemporains: Approche comparative. Paris: LexisNexis, Litec, 2008.

LEGRAND, Pierre; MUNDAY, Roderick J. C. (Orgs.). Comparative legal studies: traditions and transitions. Cambridge: Cambridge Univ. Press, 2003.

LOBBAN, Michael. A history of the philosophy of law in the common law world, 1600-1900. Londres: Springer, 2002.

LUIS, Jean-Philippe (Org.). L'État dans ses colonies: Les administrateurs de l'Empire espagnol au XIXe siècle. Madrid: Ed. de la Casa de Velásquez, 2015.

LYON-CAEN, Charles. Tableau des lois commerciales en vigueur dans les principaux états de l'Europe et de l'Amérique. Paris: A. Cotillon, 1881. 
MACFARLANE, Alan D. J. Some contributions of Maine to history and anthropology. In: DIAMOND, Alan (Org.). The Victorian Achievement of Sir Henry Maine: A Centennial Reappraisal. Cambridge: Cambridge University Press, 1991, p. 111-142.

MAINE, Henry Sumner. Village-communities in the East and West: six lectures delivered at Oxford. London: John Murray, 1871.

MANCINI, Pasquale Stanislao. Della nazionalità come fondamento del diritto delle genti. Prelezione al corso di diritto internazionale e marittimo. Turin: Tipografia Eredi Botta, 1851.

MATTHEW, H. C. G.; HARRISON, Brian Howard; BRITISH ACADEMY (Orgs.). Oxford dictionary of national biography: in association with the British Academy: from the earliest times to the year 2000. Oxford; New York: Oxford University Press, 2004. 62v.

MECCARELLI, Massimo. Le corti di cassazione nell'Italia Unita. Profili sistematici e costituzionali della giurisdizione in una prospettiva comparata (1865-1923). Milão: Giuffrè, 2005.

MERGEY, Anthony. Le réseau constitué autour d'Anthoine de Saint-Joseph et de la Concordance entre les codes civils étrangers et le Code Napoléon. Entre exaltation d'un nationalisme juridique modéré et promotion d'un fonds juridique commun. In: LE YONCOURT, Thiphaine (Org.). L'Idée de fonds juridique commun dans l'Europe du XIXe siècle: les modèles, les réformateurs, les réseaux. Rennes: Presses universitaires de Rennes, 2014. (Collection "L'univers des normes").

MERGEY, Anthony ; SOLEIL, Sylvain. Faut-il codifier le common law des États-Unis ? La controverse Sampson vs Duponceaux (1823-1826). In : CORNU-THÉNARD, N. ; MERGEY, A. ; SOLEIL, S. (dir.). La controverse. Rennes : [s. n.], 2017, no prelo.

MIROW, M. C. Andrés Bello, sucesiones, y el Código Civil francés de 1804. In: MARTINIC, M.; TAPIA, M. (Orgs.). Sesquicentenario Del Codigo Civil de Andres Bello: Pasado, Presente Y Futuro de La Codificacion. Paris: LexisNexis, 2005, p. 177 et ss.

MITTERMAIER, Carl Joseph Anton. Traité de la preuve en matière criminelle ou exposition comparée des principes de la preuve en matière criminelle, etc., et de ses applications diverses en Allemagne, en France, en Angleterre, etc. Trad. C. A. Alexandre. Paris: Cosse et N. Delamotte, 1848.

MONTANELLI, Giuseppe. Introduzione filosofica allo studio del diritto commerciale positivo. Pisa: Sampteria Pierraccini, 1847.

MOTTE, Olivier. Savigny et la France. Berne, Suisse: P. Lang, 1983.

NADELMANN, Kurt H. Pierre-Etienne Du Ponceau. Revue internationale de droit comparé, v. 5, n. 2, p. 284-290, 1953.

NEIRA, M. Martínez. Relevancia del derecho administrativo francés en la educación jurídica española : les différentes façons de percevoir et d'utiliser le droit français en tant que modèle 
juridique dans l'Europe du XIXe siècle. Forum Historiae Iuris, 2005, § 5. Disponível na internet: 〈www.forhistiur.de〉.

NEWMAN, Roger K. The Yale Biographical Dictionary of American Law. New Haven: Yale University Press, 2009.

OKUBO, Yasuo. Gustave Boissonade, père français du droit japonais moderne (1825-1910). Revue historique de droit français et étranger (1922-), v. 59, n. 1, p. 29-54, 1981.

OLIVÁN, A. De la administración con relación a España. Madrid: Boix, 1843.

ORTIZ DE ZÚÑIGA, M. Elementos de derecho administrativo. 3 vol. Granada; Imprenta e Librería de Sanz, 1842-1843.

PADOA-SCHIOPPA, Antonio. La comparazione giuridica tra Ottocento e Novecento: in memoria di Mario Rotondi, 6 novembre 1998. Milano: Istituto lombardo di scienze e lettere, 2001. (Incontro di studio).

PADOA-SCHIOPPA, Antonio. Storia del diritto in Europa: dal medioevo all'età contemporanea. Bologna: Il Mulino, 2007.

PELÁEZ, Manuel J. (Org.). Diccionario crítico de juristas españoles, portugueses y latinoamericanos (hispánicos, brasilleños, quebequenses y restantes francófonos). Málaga, Zaragoza, Barcelona: Ed. Universidad de Málaga, 2005. 5v.

POSADA DE HERRERA, J. Lecciones de administración. Madrid: Establecimento tipografico, $1843.3 \mathrm{v}$.

POUSSIELGUE, Achille. Voyage en Chine et en Mongolie de M. de Bourboulon. Paris: Hachette, 1866.

POUTHIER, Tristan. Droit naturel et droits individuels en France au dix-neuvième siècle. Tese, Paris II, 2013.

PRADEL, Jean. Histoire des doctrines pénales. Paris: Presses Universitaires de France, 1991.

RABBAN, David M. Law's history: American legal thought and the transatlantic turn to history. Cambridge: Cambridge Univ. Press, 2013. (Cambridge historical studies in American law and society).

RABBAN, David M. Methodology in legal history: From the history of free speech to the role of history in transatlantic legal thought. In: MUSSON, Anthony; STEBBINGS, Chantal (Orgs.). Making Legal History: Approaches and Methodologies. Cambridge: Cambridge University Press, 2012, p. 88-107.

Revue Internationale de droit comparé, v. 43, n. 2, p. 327-439, abr./jun. 1991.

RÉMY, Philippe. Eloge de l'exégèse. Droits, Revue française de théorie juridique, n. 1, p. 115 e ss., 1985. 
ROBERT, Jacques-Henri. Saleilles et le comparatisme. Revue d'histoire des facultés de droit et de la culture juridique, du monde des juristes et du livre juridique, p. 143-149, 1991.

ROBINEAU-WEBER, Anne-Gaëlle. A beau mentir qui vient de loin: savants, voyageurs et romanciers au XIXe siècle. Paris: Champion, 2004. (Bibliothèque de littérature générale et comparée, 55).

ROGRON, Joseph-André. Les codes français expliqués par leurs motifs. Première partie comprenant les codes politique, civil, de procédure civile, de commerce. Paris: Thorel, 1847.

ROUSSEL-ZUAZU, Chantal. La literatura de viaje española del siglo XIX, una tipología. Tese, Textas University, 2005.

SAINT-JOSEPH, Fortuné Anthoine de. Concordance entre les codes civils étrangers et le code Napoléon. Paris, Leipzig: Hingray, 1840.

SALEILLES, R. Rapport présenté à la commission d'organisation sur l'utilité, le but et le programme du congrès, 1900. In: Congrès international de droit comparé (1900). Paris: Sirey, 1905, p. 30.

SARIÑENA, Marta María Lorente. La Doctrina legal y el silenciamiento de los juristas en una España sin código (1808-1889). Quaderni fiorentini per la storia del pensiero giuridico moderno, v. 40, n. 1, p. 135-175, 2011.

SCARCIGLIA, Roberto. A brief history of legal comparison: A lesson from the Ancient to Post-Modern times. Beijing Law Review, v. 6, n. 4, p. 296-310, 2015.

SCHLOTTAU, Ralf. Deutsche Kolonialrechtspflege: Strafrecht und Strafmacht in den deutschen Schutzgebieten 1884 bis 1914. Frankfurt am Main: Lang, 2007. (Rechtshistorische Reihe).

SCHMIDT, Eberhard. Einführung in die Geschichte der deutschen Strafrechtspflege. Göttingen: Vandenhoeck, 1964.

SCHMITT, Stéphane. Aux origines de la biologie moderne: l'anatomie comparée d'Aristote à la théorie de l'évolution. Paris: Belin, 2006. (Collection Belin sup Histoire des sciencesbiologie).

SCHNYDER, Anton. Wirtschaftskollisionsrecht. Zurich: Schulthess-Schaffer, 1990.

SCHULZE, Reiner (Org.). Französisches Zivilrecht in Europa während des 19. Jahrhunderts. Berlin: Duncker \& Humblot, 1994. (Schriften zur europäischen Rechts- und Verfassungsgeschichte, Bd. 12).

SILVELA, Francisco Agustín. Colección de proyectos, dictámenes y leyes orgánicas, o estudios prácticos de administración. Madrid: Imprenta nacional, 1839. 
SMITH, Keith John Michael. Lawyers, Legislators, and Theorists: Developments in English Criminal Jurisprudence, 1800-1957. Oxford: Clarendon Press, 1998.

SOLEIL, Sylvain. In the Order of the Code Napoleon. Les carences du droit anglais au révélateur du modèle juridique français (1820-1840). In: GASNIER, F.; BLANCHARD, C. (Orgs.). Aux confins du droit, hommage amical à Xavier Martin. POitiers: LGDJ, Presses Universitaires de Poitiers, 2015, p. 377-397.

SOLEIL, Sylvain. Le modèle juridique français dans le monde: une ambition, une expansion, XVIe-XIXe siècle. Paris: IRJS Éditions, 2014. (Les voies du droit).

SOLEIL, Sylvain. Manéga en Bessarabie, Bello au Chili et Boissonade au Japon. Trois réformateurs du XIXe siècle face au modèle juridique français. Historia et Ius, n. 3, p. 1-19, 2013.

SOLEIL, Sylvain. Vasile Boerescu. In: LE YONCOURT, Thiphaine (Org.). L'Idée de fonds juridique commun dans l'Europe du XIXe siècle: les modèles, les réformateurs, les réseaux. Rennes: Presses universitaires de Rennes, 2014. (Collection “L'univers des normes"), p. 245 s.

SOLIMANO, Stefano. Codice di procedura civile italiano del 1865. In: SOLEIL, S.; HAUTEBERT, J. (Orgs.). La procédure et la construction de l'État en Europe (XVI e-XIX e siècles), Recueil de textes, présentés et commentés. Rennes: Presses universitaires de Rennes, 2011, p. 248.

STOLLEIS, Michael (Org.). Juristen: ein biographisches Lexikon; von der Antike bis zum 20. Jahrhundert. 1. Aufl. München: Beck, 2001. (Beck’sche Reihe, 1417).

STORY, Joseph. Commentaries of the conflict of laws, foreign and domestic, in regard to contracts, rights, and remedies, and especially in regard to marriages, divorces, wills, successions, and judgments. Boston: Little and Brown, 1834.

STOOS, Carl. Exposé des motifs de l'avant-projet de code pénal suisse. Tradução por Alfred Gautier. Genebra: [s. n.], 1893.

SYMEONIDES, Symeon C. American private international law. Austin, Boston, Chicago, New York, Wolters: Kluwer, 2008.

TARDE, Gabriel de. Les lois de l'imitation (1890). 2. ed. Paris: Alcan, 1895.

THOMPSON, Pishey (Org.). Sampson's Discourse, and correspondence with various learned jurists, upon the history of the law, with the addition of several essays, tracts, and documents, relating to the subject. Washington city: Gales \& Seaton, 1826.

TOUZEIL-DIVINA, Mathieu. La doctrine publiciste, 1800 - 1880: éléments de patristique administrative. Paris: Éd. La Mémoire du Droit, 2009.

TUORI, Kaius. Lawyers and savages: ancient history and legal realism in the making of legal anthropology. Oxon: Routledge, 2015. 
TUSSEAU, Guillaume. Jeremy Bentham et le droit constitutionnel: une approche de l'utilitarisme juridique. Paris: L'Harmattan, 2003. (Collection Logiques politiques).

VENAYRE, Sylvain. Panorama du voyage (1780-1920): mots, figures, pratiques. Paris: Les Belles Lettres, 2012. (Histoire).

VENTRE-DENIS, Madeleine. Joseph-Elzear Ortolan (1802-1873), un juriste dans son siècle. Revue d'histoire des facultés de droit et de la science juridique, $\mathrm{n}^{\circ}$ 16, p. 173-239, 1995.

VENTRE-DENIS, Madeleine. Joseph-Elzear Ortolan (1802-1873), un juriste dans son siècle. Revue d'histoire des facultés de droit et de la culture juridique, du monde des juristes et du livre juridique, p. 173-239, 1995.

VERNEUIL, Victor. Mes aventures au Sénégal. Paris, Jaccottet: Bourdilliat et Cie, 1858.

VIEILLARD, Eugène; DEPLANCHE, Emile. Essais sur la Nouvelle-Calédonie. Paris: LIbrairie Challamel Ainé, 1863.

VIGOUR, Cécile. La comparaison dans les sciences sociales. Paris: La découverte, 2005.

VON LISZT, Franz. La législation pénale comparée publiée par l'Union internationale de droit pénal. Berlim, Paris, Roma, Lisboa: [s. n.], 1894.

WALCKENAER, Charles-Athanase. Nouvelle collection des relations de voyage par mer et par terre. Paris: Lefèvre, 1830.

WEBER, A.-G. À beau mentir qui vient de loin : Savants, voyageurs et romanciers au XIX ${ }^{\mathrm{e}}$ siècle. Paris : Champion, 2004.

WETZELL, Richard F. Inventing the criminal: a history of German criminology, 1880 - 1945. Chapel Hill, [NC]: Univ. of North Carolina Press, 2000. (Studies in legal history).

WIGMORE, John Henry. A panorama of the World's Legal Systems. 3 v. Saint Paul: West Publishing Company, 1928.

YNTEMA, Hessel E. Le droit comparé et l'humanisme. Discours inaugural du 4 août 1958 (Ve Congrès international de droit comparé de Bruxelles, 1958). Revue internationale de droit comparé, v. 10, n. 4, p. 693-700, 1958.

ZUPETTA, L. Corso completo di legislazione penale comparata ossia commenti storicofilosofico-legali, al codice penale ed al codice di procedura criminale degli stati sardi e di tutti gli altri stati d'Italia, messi in comparazione fra di loro. Turin: Tipografia economica, 1852. 3v.

ZWEIGERT, Konrad; KÖTZ, Hein. Einführung in die Rechtsvergleichung. Tübingen: Mohr, 1996. 


\section{DADOS DA PUBLICAÇÃO}

Categoria: artigo de autor convidado.

Recebido em: 01/12/2020.

Aceito em: 02/12/2020. 


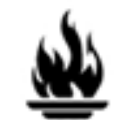

